NBER WORKING PAPER SERIES

\title{
UNDER PRESSURE: JOB SECURITY, RESOURCE ALLOCATION, AND PRODUCTIVITY IN SCHOOLS UNDER NCLB
}

\author{
Randall Reback \\ Jonah Rockoff \\ Heather L. Schwartz \\ Working Paper 16745 \\ http://www.nber.org/papers/w16745
}

\author{
NATIONAL BUREAU OF ECONOMIC RESEARCH \\ 1050 Massachusetts Avenue \\ Cambridge, MA 02138 \\ January 2011
}

We thank Steve Rivkin and David Figlio for their detailed comments, as well as participants at the American Economics Association meetings, the CALDER/Urban Institute NCLB Research Conference, the Association for Public Policy and Management conference, the International Workshop on Applied Economics of Education, and the American Education Finance Association conference for many thoughtful suggestions. This research project was made possible by funding from the Institute for Education Sciences and the Spencer Foundation, as well as seed grants from the Columbia University Institute for Social and Economic Research and Policy and Barnard College, and support from the Paul Milstein Center for Real Estate at Columbia Business School. The authors are solely responsible for any opinions or errors in the paper. Molly Alter, Daisy Chu, Ben Lockwood, Julia Zhou, Sean Tom, and especially Elizabeth Davidson provided outstanding research assistance. The authors thank the U.S. Department of Education for providing access to the restricted-use versions of the Early Childhood Longitudinal Survey and Schools and Staffing Survey. To comply with restricted-use data reporting requirements, all sample sizes in this paper have been rounded to the nearest ten. The views expressed herein are those of the authors and do not necessarily reflect the views of the National Bureau of Economic Research.

NBER working papers are circulated for discussion and comment purposes. They have not been peerreviewed or been subject to the review by the NBER Board of Directors that accompanies official NBER publications.

(C) 2011 by Randall Reback, Jonah Rockoff, and Heather L. Schwartz. All rights reserved. Short sections of text, not to exceed two paragraphs, may be quoted without explicit permission provided that full credit, including $\odot$ notice, is given to the source. 
Under Pressure: Job Security, Resource Allocation, and Productivity in Schools Under NCLB

Randall Reback, Jonah Rockoff, and Heather L. Schwartz

NBER Working Paper No. 16745

January 2011

JEL No. H4,H7,I28

\begin{abstract}
The most sweeping federal education law in decades, the No Child Left Behind (NCLB) Act, requires states to administer standardized exams and to punish schools that do not make Adequate Yearly Progress (AYP) for the fraction of students passing these exams. While the literature on school accountability is well-established, there exists no nationwide study of the strong short-term incentives created by NCLB for schools on the margin of failing AYP. We assemble the first comprehensive, national, school-level dataset concerning detailed performance measures used to calculate AYP, and demonstrate that idiosyncrasies in state policies create numerous cases where schools near the margin for satisfying their own state's AYP requirements would have almost certainly failed or almost certainly made AYP if they were located in other states. Using this variation as a means of identification, we examine the impact of NCLB on the behavior of school personnel and students' academic achievement in nationally representative samples. We find that accountability pressure from NCLB lowers teachers' perceptions of job security and causes untenured teachers in high-stakes grades to work longer hours than their peers. We also find that NCLB pressure has either neutral or positive effects on students' enjoyment of learning and their achievement gains on low-stakes exams in reading, math, and science.
\end{abstract}

Randall Reback

DepDW HQ of Economics

Barnard College, Columbia University

3009 Broadway

New York, NY 10027-6598

rreback@barnard.edu

Jonah Rockoff

Columbia University

Graduate School of Business

3022 Broadway \#603

New York, NY 10027-6903

and NBER

jonah.rockoff@columbia.edu
Heather L. Schwartz

RAND Corporation

1776 Main Street

Santa Monica, CA 90401-3208

hschwart@rand.org 
On January 8, 2002, President George W. Bush signed into law the No Child Left Behind (NCLB) Act, which many consider the most significant federal intervention into education in the United States since the authorization of the Elementary and Secondary Education Act in 1965. Under NCLB, states were required to adopt accountability systems based on student proficiency on statewide math and reading exams, and to measure proficiency within student subgroups (e.g., students from low income families, students with limited English proficiency). States must impose escalating sanctions on schools that fail to satisfy Adequate Yearly Progress (AYP) requirements for exam proficiency, including allowing students to transfer to other public schools, forcing schools to pay for students from low-income families to enroll in after-school tutoring programs, and, ultimately, closing or restructuring persistently failing schools. ${ }^{1}$

While school accountability has received much attention from economists, there is no nationwide study of the impact of NCLB on school personnel and students. We aim to fill this gap by investigating the links between the accountability incentives under NCLB and a wide array of outcomes measured for nationally representative samples. To this end, we assemble a new dataset on the determination of AYP status for schools nationwide during the introduction of NCLB, and use these data to measure the degree to which schools faced moderate or severe risks of failing. We exploit the fact that each state selects its own standardized tests and rules for satisfying AYP, generating numerous cases where a school near the margin for satisfying its own state's AYP requirements would have almost certainly failed or almost certainly passed AYP if it were located in another state. ${ }^{2}$ This allows us to implement a difference-indifferences style approach, comparing differences in outcomes for schools on and away from the AYP margin within the same state to the difference in outcomes between similar schools in other states, neither of which is on the AYP margin.

We measure outcomes in nationally representative samples of teachers and students using the non-public versions of the Schools and Staffing Survey (SASS) and the Early Childhood Longitudinal Survey (ECLS). We find that accountability pressure from NCLB reduces teachers' perceptions of job security and increases work hours, particularly among untenured teachers. We also find evidence of

\footnotetext{
${ }^{1}$ States must also publish school report cards, and schools' AYP status may affect school prestige and local property values (see Figlio and Lucas, 2004).

${ }^{2}$ As we demonstrate below, states vary widely in the percent of schools that fail to make AYP, and much of this variation is due to policy parameters (e.g., rules regarding the minimum enrollment for subgroups to count towards AYP, the grade levels that count towards AYP, and confidence or "safe harbor" adjustments to proficiency rates for schools that would otherwise have not made AYP) rather than academic achievement.
} 
teachers shifting time away from direct instruction and, for schools with very low chances of meeting NCLB requirements, away from instruction in science and social studies.

Despite concerns regarding the impact of NCLB on students, we find that short-term NCLB pressure has either positive or neutral effects on student achievement in math, reading, and science on low-stakes examinations. Students enrolled in schools with a moderate risk of failing to make AYP score 0.07 standard deviations higher in reading than comparable students in similar schools that were well above the margin for making AYP. Estimated effects for math and science are also positive (0.04 and 0.05 standard deviations, respectively) but not statistically significant in our preferred empirical specification. We also find no evidence of differential effects of NCLB pressure on students in particularly crucial subgroups or students with scores close to the passing threshold on their states' examinations. In addition, achievement gains from short-term NCLB pressure do not come at the expense of students' reported enjoyment of learning or reported anxiety over testing.

The paper proceeds as follows. In Section 2, we present a framework for how schools might be expected to respond to incentives under an accountability system like NCLB and discuss prior related empirical work. Section 3 describes the NCLB data we have collected as well as the SASS and ECLS survey data. We present our methodology and results for predictions of AYP failure probabilities in Section 4, and our estimated effects of NCLB on teachers and students in Section 5. Section 6 concludes.

\section{Conceptual Framework and Related Literature}

We first present a framework for allocation of school resources under a system of accountability such as No Child Left Behind. Schools have various resources they can use to improve student skills (e.g., school staff, curriculum, facilities, parental involvement, etc.), and all resources have associated costs. Subject to a budget constraint, schools choose an allocation based on preferences about the relative importance of helping students improve different types of skills and the relative importance of helping different types of students make improvements. There are also competing demands that constrain the amount and allocation of school resources; school staff members care about their own leisure time and local taxpayers care about their consumption of other goods and services.

More formally, we classify resources into four types: the first (denoted $u$ ) helps to improve all skills for all students (e.g., the overall effort level of teachers), the second (denoted $a_{s}$ ) is skill-specific and 
serves all students (e.g., math lessons that equally help all students learn math), the third type (denoted $b_{i}$ ) is student-specific and serves all skills (e.g., providing individual students with lessons to improve studyskills), and the fourth (denoted $c_{i s}$ ) is skill-specific and student-specific (e.g., individual math tutoring). Suppose there are two categories of student skills that schools aim to improve, one which is measured on standardized tests $(s=m)$, and another which is not $(s=z)$. Schools place weights (denoted $\left.\gamma_{i s}\right)$ on skill acquisition for each student, depending on the preferences of school staff and the community. Finally, let $l$ denote resources devoted to consumption of goods and services that are valued by the community and school staff but are unrelated to skill acquisition (e.g., teacher leisure). Schools with $N$ students and total resources equal to $K$ will choose an allocation of resources to maximize:

$$
\begin{gathered}
U(l)+\sum_{s=m, z} \sum_{i=1}^{N} \gamma_{\dot{s}} f_{\dot{s}}\left(u, a_{s}, b_{i}, c_{\dot{s}}\right) \\
\text { subject to } \sum_{s=m, z} \gamma_{\dot{s}}=1 \text { and } u+\sum_{s=m, z} a_{s}+\sum_{i}\left(b_{i}+\sum_{s=m, z} c_{i s}\right)=K-l
\end{gathered}
$$

In the equation above, the function $U$ determines the value received by community members and school staff for non-skill resources $(l)$, and the function $f_{i s}$ maps other resources into the performance of student $i$ in skill $s$. Schools choose an optimal allocation of resources given this objective function and budget constraint, which we will call "business as usual.”

A system of accountability and ratings such as NCLB introduces benefits or costs that depend on the fraction of students who pass standardized tests. Suppose that an additional resource (denoted $d_{i}$ ) is available which increases the probability that student $i$ passes the standardized tests but does not improve skill acquisition. The school now chooses an allocation of resources to maximize:

$$
\begin{aligned}
& U(l)+\sum_{s=m, z} \sum_{i=1}^{N} \gamma_{\dot{\mathrm{s}}} f_{\dot{\mathrm{s}}}\left(u, a_{s}, b_{i}, c_{\dot{\mathrm{s}}}\right)+V\left(\frac{1}{N} \sum_{i=1}^{N} g_{i}\left(u, a_{m}, b_{i}, c_{i m}, d_{i}, \varepsilon_{i}\right)\right) \\
& \text { subject to } \sum_{s=m, z} \gamma_{\dot{\mathrm{s}}}=1 \text { and } u+\sum_{s=m, z} a_{s}+\sum_{i}\left(b_{i}+\sum_{s=m, z} c_{i s}+d_{i}\right)=K-l
\end{aligned}
$$

In this equation, $\varepsilon_{i}$ is idiosyncratic noise due to imperfect test measurement (with mean zero and known variance), the function $g_{i}$ maps resources and test measurement error into whether student $i$ passes the 
standardized tests, and the function $V$ maps the school-wide pass rate into benefits or costs. ${ }^{3}$ Note that resources that do not improve measured skills $\left(a_{z}\right.$ and $\left.c_{i z}\right)$ do not enter in the function $g_{i}$.

The provisions of NCLB essentially impose costs on schools with pass rates below a certain threshold (AYP). Formally, let $V$ take the following form:

$$
V=\left\{\begin{array}{l}
\bar{V} \text { if }\left(\frac{1}{N} \sum_{i=1}^{N} g_{i}\left(u, a_{m}, b_{i}, c_{i}, d_{i}, \varepsilon_{i}\right)\right) \geq P^{*} \\
\underline{V} \text { if }\left(\frac{1}{N} \sum_{i=1}^{N} g_{\dot{s}}\left(u, a_{m}, b_{i}, c_{i}, d_{i}, \varepsilon_{i}\right)\right)<P^{*} \text { where } \bar{V}>\underline{V}
\end{array}\right.
$$

In other words, the school is worse off if the pass rate falls below some threshold $P^{*}$, but all other variation in the pass rate above or below that threshold does not have immediate consequences related to NCLB. The "all or nothing” structure has important implications for the accountability pressure different schools face. Because input allocations and the variance of test measurement error are known, schools will form expectations about their probabilities of making AYP. If a school has a very high probability of making AYP under its optimal pre-NCLB resource allocation, it will encounter very little pressure to improve and, consequently, resource allocation under NCLB should resemble "business as usual.” In contrast, if a school expects to be close to the margin of making AYP under its optimal pre-NCLB resource allocation, the school and its community will face considerable pressure to improve student pass rates. This is a key identifying assumption in our methodology. ${ }^{4}$

Most optimistically, schools will respond to accountability pressure by improving their technical efficiency or economic efficiency (or both) without any increased costs or negative effects on students' skill acquisition. For example, a school might adopt a more cost effective reading curriculum which improves $g_{i}$ for at least some students without decreasing $f_{i s}$ for any students or skills. Similarly, a school might improve economic efficiency by finding a more cost effective mix of inputs, perhaps by hiring a different mix of instructional staff to provide new combinations of $u, a_{s}, b_{i}$, and $c_{i s .}$.

\footnotetext{
${ }^{3}$ Alternatively, the function $\mathrm{V}$ could enter into the school's budget constraint, rather than the utility function, but the qualitative results from this alternative framework would be the same. Note that, for simplicity, $\mathrm{V}$ is based on the overall student proficiency rate on a single test, whereas NCLB holds schools accountable for proficiency rates for the overall student population and additional subgroups of students on both math and reading tests.

${ }^{4}$ Schools with a very low probability of making AYP in the current year will also face pressure to improve over a longer period of time. Our empirical work focuses on comparisons of schools near the margin with schools with high probabilities of making AYP, but we also test for effects of schools having low probabilities of making AYP.
} 
Without improvements to efficiency, changes in resource allocation in response to NCLB will involve tradeoffs. School personnel and community members may reduce resources devoted to consumption $(l)$ and direct them towards improving student skills. Accountability pressure may also induce schools to spend fewer resources promoting non-tested skills ( $a_{z}$ and $\left.c_{i z}\right)$, more resources promoting tested skills ( $a_{m}$ and $\left.c_{i m}\right)$, and more resources targeted to particular students $\left(b_{i}, c_{i m}\right)$ for whom extra resources will most improve their probability of passing the standardized exams. Finally, schools may allocate resources to activities that improve pass rates $\left(d_{i}\right)$ but not skill acquisition.

Most empirical research on school accountability focuses on the impacts of state and local systems, many of which preceded No Child Left Behind (e.g., Ladd \& Zelli, 2002; Hanushek \& Raymond, 2005; Chakrabarti, 2007; Rouse et al., 2007; Chiang, 2009; Rockoff \& Turner, 2010). Several studies find evidence that accountability pressure causes schools to reallocate resources in ways that raise average student achievement. However, schools have also been found to shift resources towards students and subjects that are most critical to the accountability rating (e.g., Booher-Jennings, 2005; Reback, 2008; Neal \& Whitmore Schanzenbach, 2010), teach to the test (Jacob, 2005; Figlio \& Rouse, 2006), remove low performing students from the testing pool (Figlio \& Getzler, 2006; Figlio, 2006, Cullen \& Reback, 2006), or cheat (Jacob \& Levitt, 2003).

Knowledge about the impacts of NCLB is still nascent. Among the few studies that apply rigorous methods, most examine only student performance on high stakes tests in one state or one city (Springer, 2008; Krieg, 2008; Ladd \& Lauen, 2010; and Neal \& Whitmore Schanzenbach, 2010). These studies have found that students enrolled in schools failing AYP tend to make greater than expected gains on high-stakes tests, though there is conflicting evidence concerning heterogeneous effects on students at different parts of the performance spectrum. Only two prior studies examine the impact of NCLB incentives in multiple states. Ballou and Springer (2008) examine variation in the grade levels tested for NCLB across seven states and find that students generally perform better on low-stakes exams during years when they took high-stakes tests, particularly for students near the margin of passing their highstakes exams. Dee and Jacob (2009) find that students in states with no prior accountability policies experienced greater increases on the National Assessment of Educational Progress in some grades and subjects after NCLB was introduced. 


\section{Data and Descriptive Analysis}

\subsection{Data Description}

Our analysis focuses on the initial years of NCLB implementation following its passage in January 2002. To measure NCLB pressure faced by schools during these years (and which subgroups and subjects caused that pressure), our analysis requires a comprehensive, national database of schools' NCLB-related outcomes. Because NCLB did not require states to report these data to the federal government, we painstakingly collected them from individual school report cards or state-level data files wherever available, and supplemented remaining states' data with two existing but incomplete public datasets. ${ }^{5}$ We present the categories of data collected and their sources in Appendix 1.

We examine teacher-level outcomes from the 2003-2004 wave of the SASS and student-level outcomes from the spring 2004 wave of the ECLS, when most students in the ECLS were in the fifth grade. These surveys are sponsored and distributed by the National Center for Education Statistics. We use the non-public-use versions of these data in order to link teachers and students to our constructed measures of the degree to which NCLB placed short-term pressure on their school to make AYP.

The SASS surveyed teachers in all 50 states and allows researchers to construct nationallyrepresentative samples with the use of sampling weights. ${ }^{6}$ For consistency with our examination of student outcomes in the ECLS, we limit the sample of teachers to those working in regular public schools that served at least five fifth graders as of 2001-2002. The first panel of Table 1 provides summary statistics on the outcome variables we create from SASS survey questions. ${ }^{7}$

The ECLS followed students for nine years, collecting data in both the fall and the spring of the school years 1998-1999 and 1999-2000 (kindergarten and first grade), and in the spring of the school years 2001-2002, 2003-2004, and 2006-2007 (third grade, fifth grade, and eighth grade). The ECLS has

\footnotetext{
${ }^{5}$ These two sources of NCLB-related data are the Council of Chief State of School Officers' School Data Direct (http://www.schooldatadirect.org/) and the American Institutes for Research National AYP and Identification Database (http://www.air.org/publications/naypi.data.download.aspx). Whereas the first source includes AYP data in most states for the years 2002-2003 through the current year, the latter dataset includes states' yes/no determinations regarding 2003-2004 and 2004-2005 subgroups and schools' passage of AYP participation and proficiency targets. In addition to missing data for some states, these sources also contain discrepancies with states' school report cards. We prioritized school report card data where available since they are the final interface between schools and the public and should reflect final adjustments such as school appeals to states' determinations of AYP. ${ }^{6}$ The SASS surveyed administrators but we did not feel these questions were relevant to NCLB pressure. Although the ECLS surveyed teachers, the SASS offers a much larger sample size, surveys teachers across all grades levels, and asks them pertinent survey questions about their time use, attitudes toward their job, and future career plans.

${ }^{7}$ We recoded teachers' reported work-related hours and instructional hours as missing if their reported 60 or more instructional hours, a suspiciously high level of reported instructional time given the typical five day school week.
} 
the widest coverage and array of student-level outcomes of any nationally representative longitudinal dataset covering years before and after the passage of NCLB. Indeed, the timing of the ECLS survey is serendipitous, as this cohort was tested just prior to the first year of NCLB and again two years later. The ECLS sample was designed to be representative of kindergartners, their classrooms, and their schools in the school year 1998-1999, (and representative of first grade students in 1999-2000). It includes students from 40 relatively populous states. ${ }^{8}$

The student-level data collection procedures in the ECLS result in samples of students that are not necessarily representative of the student populations at their schools, particularly due to tracking procedures for students making non-structural school transfers. ${ }^{9}$ In our analysis of ECLS data, we use sampling weights to make our estimates nationally representative. However, we test the robustness of our results to dropping child-level sampling weights and removing students who made non-structural enrollment changes. This alternative specification does not change our main conclusions and has small effects on the precision of our estimates, increasing precision in some cases and reducing it in others.

In the ECLS data, we are particularly interested in measures of student performance on a series of standardized tests in math, reading, and science. Unlike the tests that states administer under NCLB, the ECLS tests were low-stakes, un-timed, and adaptive (i.e., subsequent questions are selected based on a student's performance on preceding questions), thus preventing floor or ceiling effects and increasing test reliability. Students and schools became involved in the ECLS survey well before NCLB, and likely were familiar with the ECLS surveyors and understood that these tests were not high-stakes. This reduces concerns about teaching to the ECLS test or strategic responses to survey questions. Also, by examining tests unrelated to NCLB, we avoid problems of mean reversion due to measurement error or other shocks to high-stakes test scores that do not reflect real achievement but would nevertheless affect the accountability pressure faced by the school.

\footnotetext{
${ }^{8}$ It used a multistage probability sample design, first selecting broad geographic areas (e.g., a county), then schools within each area, and finally students within schools. On average, 23 kindergarteners were sampled in each school. ${ }^{9}$ The ECLS includes students who were retained within the same grade or skipped a grade level, but has some attrition. In the school year 1999-2000, a randomly-selected 50 percent sub-sample of students who transferred from their original school was surveyed, and another random sample of first graders in the same schools where transfer students were followed was added. However, this "freshening" of the sample was not repeated in the third, fifth, and eighth grades, and the ECLS simply sampled 50 percent of students who transferred schools for nonstructural reasons (i.e., students who switched schools for reasons other than moving from a K- $4^{\text {th }}$ grade school to a $5^{\text {th }}-8^{\text {th }}$ grade school in the same district).
} 
The second panel of Table 1 provides descriptive statistics for our ECLS outcome measures. Since most surveyed students in the ECLS spring 2004 wave were fifth graders, we limit the sample of students to those attending regular public schools in the spring of the school year 2003-2004 that also served at least five fifth grade students as of 2001-2002. We standardize students' scores within subject and year so that the national mean score equals zero and the national standard deviation equals one. ${ }^{10}$ In additional to standardized exams, we examine students' reported enjoyment of math and reading, as well as reported anxiety over standardized tests. ${ }^{11}$

Table 2 provides descriptive statistics on control variables used in our regression analyses. We show statistics separately for our samples of public school teachers from the SASS and public school students from the ECLS. Along with variables from the surveys themselves, we also use school characteristics from the Common Core of Data (CCD), compiled by the National Center for Education Statistics (NCES), and aggregated student test performance variables from the National Longitudinal School-Level State Assessment Score Database (compiled by American Institutes for Research). ${ }^{12}$ We standardize test performance variables within states to have a mean of zero and standard deviation one. In addition to our analysis of the SASS and ECLS data, we examine a set of survey responses from the Implementing Standards-Based Accountability (ISBA) study, conducted by the RAND Corporation. As part of ISBA, principals and math teachers in three states (Pennsylvania, Georgia, and California) were surveyed regarding their views on NCLB-related policies and the implementation of these policies in their schools. While these data are not public, researchers at RAND generously provided us with cross-tabulations of survey responses on a number of items, broken down by our measure of NCLB pressure. We discuss our measure of pressure and present the ISBA results in Section 4.

\footnotetext{
${ }^{10}$ The ECLS data report t-scores of students' IRT-based "theta scores,” which are estimates of students' skill levels. These t-scores are already constructed so that the national (cross-sectional) mean equals 50 and the national standard deviation equals 10, so we simply subtract 50 from these scores and then divide by 10 to convert them to Z-scores. Our sample means and standard deviations for these variables are not exactly equal to 0 and 1 , respectively, because we must exclude a small fraction of states and schools with missing data, and because we use longitudinal student sample weights rather than cross-sectional sample weights.

${ }^{11}$ Answers to these specific questions, rather than an index based on a larger set of items, were obtained via special application to the National Center for Education Statistics. Due to copyright restrictions we cannot report the exact wording of these questions. For interest in and enjoyment of math and reading, we create dependent variables by summing the subject-specific numeric values for four relevant questions. We use only one question regarding feelings of test anxiety and create an indicator for reporting that such feelings were "mostly" or "very" true.

${ }^{12}$ Tennessee did not report school level demographic information to the federal government after 1998-1999. Rather than drop Tennessee from our analysis, we use data from 1998-1999 in lieu of data from 2001-2002.
} 


\subsection{Descriptive Analysis of AYP Outcomes under NCLB}

For a school to make AYP, each of its numerically significant student subgroups must meet a test proficiency rate threshold in both math and reading in addition to a test participation cutoff of 95 percent. Secondary schools must also meet thresholds for graduation rates, and primary schools must also perform sufficiently well on a state-selected "additional indicator," typically the attendance rate. Beyond these general parameters, states have a great deal of flexibility in setting a number of other rules and regulations. Specifically, states must:

- $\quad$ select standardized tests in math, reading, and (starting in 2007-2008) science;

- $\quad$ select which grade levels to test (until 2005-2006) ${ }^{13}$;

- $\quad$ establish proficiency rate thresholds, i.e., the percent of students that must score proficient or higher. Thresholds apply to the whole school as well as individual subgroups;

- determine whether to calculate proficiency rates using all students across tested grade levels within each school or within tested grade levels; ${ }^{14}$

- determine whether to calculate subgroup proficiency rates using multiple years of testing;

- define continuous enrollment, where only continuously enrolled students count towards calculation of subgroup size as well as test participation and proficiency rates;

- $\quad$ select the minimum number of students that must be enrolled in tested grade levels for a student subgroup to be numerically significant and thus count towards a school's AYP determination;

- determine the generosity of confidence intervals applied to student subgroups' raw proficiency rates, which effectively lower proficiency thresholds needed to make AYP;

- determine the nature of safe harbor provisions that allow schools to make AYP in spite of a subgroup not meeting the required proficiency rate that year; and,

- $\quad$ decide upon the appeals process for schools to appeal their AYP status from the state.

\footnotetext{
${ }^{13}$ From 2003 to 2005, states were allowed to choose which tested grade levels counted towards AYP determination, so long as at least one level in each of three grade spans (3-5, 6-9, and 10-12) were included. Only beginning in 2005-2006 did states have to assess the math and reading proficiency of all third through eighth graders and at least one level for grades 10 to 12 .

${ }^{14}$ While most states determine subgroup size using students across all tested grades within a school, eight states (Arizona, Colorado, Maine, New York, New Jersey, Rhode Island, Tennessee, and Washington) further disaggregate subgroup size and subgroup results to the grade or grade span level.
} 
Even this long list does not fully capture all the minutiae of NCLB rulemaking. For example, while most states consider the performance of five ethnic subgroups (Asian/Pacific Islander, black, Hispanic, Native American, and white) in their AYP determinations, California and Alaska add additional subgroups (Filipino and Alaskan Native, respectively) while Asian/Pacific Islander is not an AYP subgroup in Texas.

These seemingly esoteric decisions have real implications for whether schools fail to meet the targets set for them under NCLB, as can be seen in the remarkable amount of variation in the fraction of schools in each state that made AYP. In 2003, most states' failure rates fell between 20 and 40 percent, but the range extended from roughly 1 percent in Iowa to 82 percent in Florida (see Figure 1).

Importantly for our study, variation in the fraction of schools making AYP was mostly a function of states’ rulemaking choices and bears little relation to measures of statewide academic achievement. For example, the fraction of schools failing to make AYP by state is not significantly correlated with the fraction of students in the state deemed proficient on the state's own exams, because required proficiency rates were often set at the $20^{\text {th }}$ percentile of baseline (spring 2002) school performance. ${ }^{15}$ More importantly, as shown in Figure 2, there is little relationship between the fraction of schools failing to make AYP in a state and the state's average student achievement as measured on the National Assessment of Educational Progress (NAEP), a federal exam that has been administered to nationally representative samples of students in grades 4 and 8 for several decades. ${ }^{16}$ States with the highest NAEP proficiency rates have slightly lower AYP failure rates than other states, but this relationship is not statistically significant and NAEP proficiency rates explain very little of the cross-state variation in AYP failure rates.

We have been unable to find any single aspect of NCLB design that can explain the wide variation in failure rates. However, by testing a number of factors we have come to the conclusion that interaction of four features significantly influences the fraction of schools failing AYP: (1) state rules for the numerical significance of student subgroups; (2) within-school heterogeneity, which influences how many student subgroups are numerically significant; (3) the generosity of the state's confidence intervals; and (4) the generosity of the state's safe harbor provisions. The complex manner in which these policy

\footnotetext{
${ }^{15}$ However, there was even wide variation in how states calculated the $20^{\text {th }}$ percentile. For example, some states based the $20^{\text {th }}$ percentile measure on baseline school-wide pass rates and some used grade-specific and/or subjectspecific baseline pass rates.

${ }^{16}$ Note that we plot AYP failure rates for schools serving fifth grade students, which is the type of schools we analyze in SASS and ECLS. In Figure 1, AYP failure rates are shown for all schools that receive AYP designations.
} 
details interact increases our confidence that the wide differences in the apparent leniency of NCLB requirements across states can help identify its impact on schools and students.

\section{Predicting the Probability of Failing AYP}

In the first stage of our analysis, we use our newly assembled data set to determine which student subgroups and, by extension, which schools were on the margin of failing to make AYP in the first two years during which NCLB was in effect. We begin by estimating state- and subject-specific probit regressions to generate predictions of the likelihood that each numerically-significant student subgroup would pass AYP proficiency targets in the spring of both 2003 and 2004. To do so, we use school demographic characteristics (listed in Table 2) and 2001-2002 subgroup-level/school-level test performance variables from the school year 2001-2002 — after the passage of NCLB but prior to the first AYP determinations. ${ }^{17}$ We conduct regressions separately by state, so that coefficients capture the nuances of how states' NCLB rules affect schools' chances of making AYP. Regressions are run at the student subgroup level and are restricted to those that were numerically significant in either 2003 or 2004. ${ }^{18}$ Because of the variation in NCLB rules across states, our variables differ somewhat across some states. To be as consistent as possible, we applied a set of rules (described in Appendix 2) for how to specify our regressions conditional on the available data.

For each subject $s$, we estimate state-specific regressions of the following form:

(4) $A Y P_{j k s 03-04}= \begin{cases}1 & \text { if } \alpha_{q}+X_{j k s 02} \beta_{1}+N_{j k s 04} \beta_{2}+X N_{j k s} \beta_{3}+W_{j 02} \beta_{4}+M_{j k s 03-04} \beta_{5}+\zeta_{j k s}>0 \\ 0 & \text { otherwise }\end{cases}$

where $A Y P_{j k s 03-04}$ denotes whether subgroup $k$ at school $j$ met its AYP proficiency rate targets in 2003 and 2004 in subject $s$. $X_{j k s 02}$ is a vector of test score variables for subgroup $k$ based on performance on statewide exams in subject $s$ during the school year 2001-2002, $N_{j k s 04}$ is a vector of student subgroup size

\footnotetext{
${ }^{17}$ In the vast majority of states, student test performance during the 2001-2002 school year did not directly affect the proficiency rates used to formulate schools' AYP determinations during 2002-2003 or 2003-2004. A few states incorporated 2001-2002 proficiency rates into 2002-2003 AYP determinations by generating two-year or three-year average proficiency rates for student subgroups; the remaining states used contemporaneous proficiency rates. Most states calculated a "safe harbor" provision whereby a school could make AYP if the only subgroup not meeting its target proficiency rate demonstrated sufficient improvement from the prior year. In 2002-2003, this would be based on performance relative to 2001-2002.

${ }^{18}$ This means a single school will have as many AYP predictions per subject (math or reading) as it has numerically significant student subgroups. For states that further disaggregate subgroup results to the grade or grade span level, we also define subgroups at this disaggregated level.
} 
variables in subject $s$ for subgroup $k$ in 2004, $X N_{j k s}$ represents interactions of test score and subgroup size variables, $W_{j 02}$ is a vector of control variables for school-level demographics from the school year 20012002 (listed in Table 2), and $M_{j k s 03-04}$ is a vector of two dichotomous indicators for whether student subgroup $j$ was numerically significant in subject $s$ in only 2002-2003 or only 2003-2004, and $\zeta_{j k s}$ is a normally distributed disturbance term. The $X_{j k s 2}$ vector includes cubic terms for the test performance in subject $s$ among students in subgroup $k$ at school $j .{ }^{19}$ The subgroup size variables $\left(N_{j k s 04}\right)$ and interactions with test score measures $\left(X N_{j k s}\right)$ are included to account for states' confidence interval adjustments and the mechanical decrease in the error variance of student pass rates as the number of tested students within subgroup $k$ increases. In particular, the $N_{j k s 04}$ vector contains cubic terms for the inverse of the square root of the number of accountable test-taking students in subject $s$ in subgroup $k$ in school $j$ during the school. We exclude subgroups from our sample if they were too small to be accountable under AYP in both 2003 and 2004. Appendix 2 provides detailed descriptions of each predictor and its data source.

We restrict our sample to schools that were (a) operational from at least 2001-2002 through 20032004, (b) neither technical/vocational nor only for special education students according to the classifications in the Common Core of Data and (c) served at least five students in grade 5 as of the school year 2001-2002. ${ }^{20}$ We are forced to omit nine states from the SASS sample and five states from the ECLS sample due to missing data (e.g., 2002 test scores or a state’s AYP determinations for subgroups). Our numerous attempts at gathering these data from state departments of education have either been unsuccessful or, in most cases, states claim that the data simply do not exist or are too

\footnotetext{
${ }^{19}$ Because we focus on schools serving fifth grade, we prioritize using fifth grade students' 2001-2002 proficiency rates for these control variables. Because some states either did not test fifth graders in 2001-2002 or disaggregated 2002-2003/2003-2004 subgroup AYP status by grade level, the 2001-2002 test performance variables are in some cases based either in part or wholly on tests from other grades, typically grade 4 or grade 6; full details are provided in Appendix 2. In addition, subgroup-specific performance for 2001-2002 is unavailable for some states, in which case we use overall student test performance in subject $s$, and include interaction terms between test performance and the fraction of the overall student population at each school comprised of students in group $k$. In practice, we find that subgroup-specific and overall measures of pre-NCLB test score performance work equally well in predicting the likelihood that the schools' pass rates will be near the NCLB required cutoff in 2003-2004.

${ }^{20}$ We use the restriction of having five fifth graders because some schools that should serve grade 5 according to grade level ranges indicated in the CCD actually enrolled no fifth graders. In cases where we use test performance from a grade other than grade 5 in the $X_{j k s 02}$ vector, the regressions also include subgroups from schools serving the tested grade even if the school does not serve grade 5 . For example, if a state tested fourth graders but not fifth graders in 2001-2002, we use grade 4 test performance in $X_{j k s 02}$ and include K-4 schools in our first stage. Full details are provided in Appendix 2.
} 
unreliable to release. Fortunately, these states have relatively small populations; more than 92 percent of the U.S. population resides in one of the 41 states with sufficient data for our analyses.

\subsection{Defining the AYP Margin}

We use predicted subgroup-level AYP pass probabilities from the state- and subject-specific regressions in Equation 4 to construct measures of accountability pressure under NCLB. Our measures are based on the following logic. Schools where all numerically significant subgroups have high chances of passing state proficiency targets in both math and reading likely faced little NCLB pressure. In contrast, schools where any numerically significant subgroup was close to the margin of passing are likely to have faced accountability pressure. However, schools where any subgroup has a very low probability of passing are unlikely to be able to do anything to change their AYP outcome in the short term.

Following this logic, we construct the following school level measures of NCLB pressure:

(i) A school is classified as above the AYP margin if all numerically significant subgroups have a high chance of making AYP in both math and reading;

(ii) A school is classified as below the AYP margin if it has at least one numerically significant subgroup with a low chance of making AYP in either math or reading;

(iii) A school is classified as on the AYP margin for a particular subject if (a) at least one numerically significant subgroup in the school has a moderate chance of making AYP in that subject, and (b) no numerically significant subgroup in the school has a low chance of making AYP in either subject;

(iv) A school is classified as on the AYP margin if it is on the AYP margin for math or reading.

For all of our analyses below, we define a "moderate chance" of a subgroup making AYP as between 25 and 75 percent, a "high chance" as above 75 percent, and a "low chance” as less than 25 percent. While these cutoffs are admittedly ad hoc, our results are not very sensitive to using other cutoffs ranging from between 35 and 65 percent to between 15 and 85 percent.

Table 3 summarizes our measures of NCLB pressure for schools in these 41 states. We classify 69.1 percent of schools above the AYP margin, 21.4 percent on the AYP margin, and 9.5 percent below the AYP margin. The actual rates with which schools made AYP in both 2003 and 2004 were 87 percent for schools above the margin, 38 percent for schools on the margin, and 7 percent for schools below the margin, demonstrating that our specification has sufficient power to identify substantial variation in which 
schools were at risk of failing to make AYP. However, our analyses below are predicated on the idea that the risks of AYP failure were foreseeable to school administrators and teachers. To the extent that measurement error causes us to misclassify which schools believed they were on the AYP margin, our estimated effects of NCLB pressure may be biased towards zero. This possibility motivates the need to examine whether our estimates are related to teachers' and administrators' reported sense of accountability pressure, which we do below.

The results reported in Table 3 also reveal that, with the exception of white and economically disadvantaged students, most student subgroups were typically not numerically significant and did not count towards AYP. For example, 70 percent of schools did not have a sufficient number of disabled (special education) students in either 2003 or 2004 to be held accountable for that group’s performance. This rate varied across states depending on minimum subgroup size requirements, again underscoring the importance of these regulations. For example, disabled subgroups were accountable under NCLB in either 2003 or 2004 in just 7 percent of Arizona schools, compared with 61 percent in Massachusetts.

Among subgroups that were numerically significant and thus accountable, the fraction we predict to have a moderate or low chance of making AYP varies considerably. The subgroups most frequently predicted to have a moderate chance of passing in reading were disabled and limited English proficient (30 and 37 percent, respectively) and, in math, disabled and Black (26 and 27 percent, respectively). Disabled student subgroups also have relatively high fractions (about 15 percent) predicted to have low chances of passing proficiency targets in both subjects, as do Native American subgroups (17 percent in math, 22 percent in reading) and Asian subgroups in reading (25 percent). In contrast, White subgroups are nearly always predicted to have a high chance of passing proficiency targets.

\subsection{Variation in Predicted NCLB Pressure across States}

Our identification strategy is predicated on the idea that similar schools faced different levels of NCLB pressure because of the state in which they were located. However, it is still broadly true that schools with high average achievement had greater chances of making AYP than schools with low average achievement. To illustrate both of these ideas, we take our primary measure of NCLB pressurewhether a school was on the AYP margin — and plot cumulative distributions of the percent of schools on 
the margin across 41 states, separating schools by quartile of within-state campus-wide test score performance in the school year 2001-2002.

As expected, we place more schools on the AYP margin within the lowest performance quartile, but being on the margin is by no means the exclusive territory of low scoring schools (Figure 3, top panel). The median state has 60 percent of its lowest quartile schools on the AYP margin, but also has 25 percent of its second quartile, 10 percent of its third quartile, and 5 percent of the top performing quartile on the AYP margin. Importantly, in all of our analyses below, we always include flexible controls for schools' relative performance on statewide examinations in the school year 2001-2002. Thus, our identification is not based on the general tendency of low-scoring schools to face more NCLB pressure.

These cumulative distributions also illustrate that we put many relatively high performing schools on the AYP margin in some states with "tough” NCLB rules. In 20 percent of states, the percentages of schools on the AYP margin in the lowest through highest performing quartiles were at least 80 percent, 50 percent, 25 percent, and 10 percent, respectively. In contrast, for the 20 percent of states that appear to have the lowest amount of NCLB pressure, the percentages of schools on the AYP margin in the lowest through highest performing quartiles were at most 40, 12, 5, and 3 percent, respectively.

When we plot similar cumulative distributions for the percentage of schools we place below the AYP margin, we see less variation but similar qualitative results (see Figure 3, bottom panel). As expected, far more schools are below the margin in the bottom quartile of school test performance. Nevertheless, we place hardly any schools below the margin in a few states, while in some states we place a substantial fraction of schools below the margin in the second or third quartiles of within-state performance. In other words, schools with reasonably good test scores still had a low chance of passing AYP in some states with “tough” NCLB rules.

\subsection{Assessing our Measure of NCLB Pressure in the ISBA Surveys}

To get an initial sense of the validity of our measures of NCLB pressure, we examine aggregate statistics from surveys of principals and math teachers in California, Pennsylvania, and Georgia by the RAND Corporation concerning topics related to NCLB in the school-year 2003-2004. As mentioned in Section 3, the micro data from these surveys are not publicly available and we present these crosstabulations as suggestive evidence. We pursue a more rigorous methodology in Section 5. 
We are only able to examine principals' survey responses in 21 schools that we classified as on the AYP margin and 104 schools above the AYP margin. No principals were surveyed at any school that we predict had a low chance of making AYP. Among principals working in schools above the AYP margin, 96 percent felt they would make AYP in the school year 2003-2004, relative to only 71 percent who worked in schools on the AYP margin. Indeed, among principals in schools above the AYP margin, 72 percent felt they would make AYP for the next five years, relative to only 48 percent in the marginal group (Table 4, Panel A). Principals in schools on the AYP margin were between 9 and 14 percentage points more likely to say that they had: encouraged teachers to focus more time on tested subjects; distributed commercial test preparation materials; or distributed copies of previous state tests or test items. All of these differences in responses across principals in the two groups are statistically significant at approximately the one percent level.

Because of the larger number of teachers surveyed, we can examine teachers working in schools we classify as below the margin (19 teachers), on the margin (224 teachers), and above the margin (1,074 teachers) of AYP. Relevant survey questions included probes about teaching test-taking strategies, focusing on students who are close to proficient on the high stakes test, emphasizing the topics and types of problems given on the state test, spending more time teaching content, and searching for more effective teaching methods. Teachers working in schools on the AYP margin were between 11 and 19 percentage points more likely than teachers working in schools above the AYP margin to report having taken these actions, while teachers in schools below the AYP margin were between 3 and 20 percentage points more likely to report having taken these actions than teachers in schools on the margin. All of the differences between responses from teachers in the schools above the margin and either of the other two teacher groups are statistically significant at the one percent level, and help confirm that our constructed measures of NCLB pressure align with principals’ and teachers’ reported perceptions.

\section{Estimates of the Impact of Accountability Pressure Under NCLB}

We use our measures of whether a school is below, on, or above the AYP margin to predict various outcomes for an individual $i$ (i.e., a student or teacher) in school $j$ and state $q$. Our basic regression specification is shown by Equation 5:

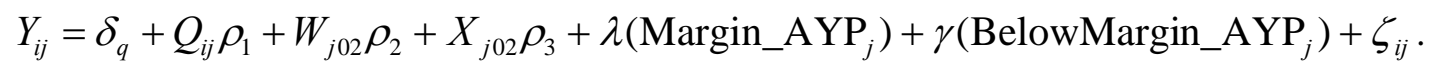


$Y_{i j}$ is an outcome of interest, $\delta_{q}$ represents state fixed effects, $Q_{i j}$ is a vector of (student- or teacher-level) control variables, and $W_{j 02}$ is a vector of school-level control variables (as in Equation 4). The $X_{j 02}$ vector differs slightly from the $X_{j k s 02}$ vector in Equation 4 in that it contains school-wide student achievement measures in reading and math during the school year 2001-2002, normalized within the state to have a mean of zero and standard deviation of one, and the square and cube of these achievement measures.

The coefficient of interest is $\lambda$, which represents the average impact of the NCLB pressure associated with being in a school on the AYP margin. This estimate of $\lambda$ measures the causal effect of short-term accountability pressure under the assumption that, conditional on a host of observable school characteristics, the variation across states in whether a school falls on the AYP margin is exogenous. We believe that the evidence presented in Section 3 provides ample support for this identification strategy. The estimate of $\gamma$ (i.e., the impact of NCLB pressure associated with being below the AYP margin) is less well-identified and should be interpreted more cautiously, though there are likely very few schools that would find themselves below the AYP margin in every state nationwide (see Figure 3). Nevertheless, because few schools are predicted to be below the AYP margin, our estimates of $\lambda$ always remain qualitatively similar if we drop the "below margin” indicator $(\gamma)$ from the regressions.

Because our measures of NCLB pressure are derived from first stage probit regressions, we estimate standard errors using a two-sample bootstrap adjusted for school-level clustering. We use 1,000 Monte Carlo simulations of both the first- and second-stage models, randomly sampling coefficients from the first-stage model using the implied distribution from the variance-covariance matrix which allows for school clustering, and randomly sampling schools (with replacement) in the second-stage models.

\subsection{Impacts on Teachers}

We examine the effect of NCLB pressure on teachers using the SASS data from 2003-2004. Because many of these teachers do not teach students or subjects tested under NCLB, we augment Equation 5 with an indicator for whether the teacher taught math or reading in a NCLB-tested grade and

interact this with the indicators for whether the school was on or below the AYP margin. ${ }^{21}$ The $Q_{i j}$ vector

\footnotetext{
${ }^{21}$ In cases of teachers covering multiple grades, we set the "high-stakes grade/subject” indicator variable equal to one if the teacher covers either math or reading and more than half of the teacher's covered grade levels were tested for NCLB in that teacher's state during the spring of 2004.
} 
includes the teacher-level control variables listed in Table 2, with both linear and squared terms for teachers' years of experience.

The first column of Table 5 (Panel A) displays estimated effects of NCLB pressure on whether teachers strongly agreed with the statement: "I worry about the security of my job because of the performance of my students on state and/or local tests.” Compared to teachers of high-stakes grades/subjects at schools above the AYP margin, those in schools on the AYP margin are 5 percentage points more likely to report concern over their job security related to student test performance-a large increase considering that only 7.5 percent of teachers reported this concern overall. Like the ISBA results above, this supports the notion that our measure of NCLB pressure is valid and captures significant variation in school staff members' perceptions of pressure. Column 1 in Panel B of Table 5 displays estimates from a specification that restricts the sample to untenured teachers. ${ }^{22}$ Although the resulting drop in the number of observations decreases our precision significantly, we do find that untenured teachers working in schools below the AYP margin, even those not teaching high-stakes grades/subjects, tend to be very concerned about how student test performance will affect their job security.

We next examine how NCLB pressure affects teachers' long-term career plans. We construct an indicator variable from teachers' survey responses concerning whether they plan to teach until retirement. If a school is on the AYP margin, untenured teachers are at least as likely to have long-term teaching career plans as their counterparts teaching in schools with higher probabilities of making AYP. However, teachers working in high-stakes grades/subjects in a school below the AYP margin are 13 percentage points less likely to plan to teach until retirement than those working in a school above the AYP margin (Table 5, Panel A, Column 2). This is in line with findings by Feng et al. (2010) that schools in Florida that received very low accountability ratings subsequently experienced higher rates of teacher turnover. The effect is stronger for untenured teachers (Table 5, Panel B, Column 2), suggesting that teachers at greatest risk of job loss might be discouraged by the challenge of raising student proficiency rates at schools that are unlikely to make AYP and face state sanctions.

The third column of Table 5 presents results concerning how NCLB pressure affects teachers' total weekly work hours, measured several months ahead of NCLB testing. The largest and most

\footnotetext{
${ }^{22}$ The SASS does not measure tenure, so we created an indicator for whether a teacher's total years of experience (measured in the SASS) exceeds the state's required number of years for tenure. Data on state requirements come from 2002-2003, see Brunner and Imazeki (forthcoming), and we thank Eric Brunner for providing them.
} 
significant differences in work hours occur for untenured teachers who work in high-stakes areas at schools on the AYP margin. These teachers report working about four hours more per week than their untenured co-workers teaching low-stakes grades/subjects at their schools, a difference with a $p$-value of $0.03 .^{23}$ Given that the standard deviation of work hours is under 10 hours (see Table 1), this difference in hours worked by untenured teachers is substantial.

We also estimate the impact of NCLB pressure on teachers' self-reported number of instructional hours per week, which is a subset of their total work hours. Unlike total hours, instructional hours do not increase for any type of teacher in response to NCLB pressure (Table 5, Column 4). Moreover, instructional hours actually decline by one to two hours per week for teachers in schools below the AYP margin and for untenured teachers in schools on the AYP margin, though not differentially for those teaching high-stakes grades/subjects. The fact that untenured teachers in schools facing short-term NCLB pressure report working more hours but spending less time on instruction presumably means that part of their work day shifts towards other activities such as student assessment, grading, lesson planning, or other non-instructional activities. This heightens the concern that NCLB pressure may have negative effects on student achievement, particularly for material not covered on high-stakes exams, and provides further motivation for our analysis of student outcomes via the ECLS data.

In the SASS data, surveyed teachers are randomly selected within each school, so their activities should be an unbiased (albeit noisy) measure for all teachers in the school. Nevertheless, one concern for our analysis is that principals at schools facing NCLB pressure strategically place teachers into highstakes grades and subjects. However, we believe such behavior would most likely create bias against our findings. If principals wish to boost high-stakes test performance, they should assign their most talented teachers to high-stakes areas. Yet we find these teachers are more concerned about their job security, are less likely to plan to teach until retirement, and work longer hours only if they do not have tenure.

While the SASS data are too coarse to identify the specific activities to which teachers devote more time, we can explore shifts in instructional time across subject areas using self-reports of teaching content during the previous week. The SASS surveyed teachers in the fall, well ahead of NCLB testing,

\footnotetext{
${ }^{23}$ We computed the p-value of this estimate using the bootstrapped standard error for the sum of the relevant coefficients. The 3.07 point estimate for the interaction of teaching high-stakes with working in a school on the AYP margin is marginally significant, with a p-value of .11, suggesting that high-stakes teachers in schools under accountability pressure also work longer hours than high-stakes teachers in schools facing little pressure under NCLB.
} 
and survey responses should reflect general shifts in instruction rather than last-minute preparation for high-stakes tests. To examine whether NCLB pressure shifted resources away from low-stakes subjects, we focus on whether the teacher taught at least one science lesson or at least one social studies lesson during the prior week. The estimates displayed in Table 6 suggest that schools on the AYP margin slightly change the proportion of teachers offering science lessons. Compared to teachers at schools above the margin, these teachers are 4.0 percentage points less likely to have taught a science lesson in the last week. They are also 1.3 percentage points less likely to have taught a social science lesson, but this estimate is not statistically significant. The effects on science and social studies offerings in schools below the AYP margin are even larger and both statistically significant. Compared to teachers at schools above the margin, teachers in schools with a low chance of making AYP are 10 percentage points less likely to offer a science lesson and 6 percentage points less likely to offer a social studies lesson. These are large differences considering that 63 percent and 65 percent of teachers in this sample taught science and social studies lessons, respectively, in the previous week (see Table 1). Schools with little short-term chance of making AYP may still try to shift instruction toward the high-stakes subjects in order increase their chances of eventually making AYP. ${ }^{24}$

\subsection{Impacts on Students}

Changes in teachers' work and instructional time measured in the SASS data provide somewhat ambiguous evidence on whether NCLB pressure leads to broad increases in student achievement or a more narrow focus on the material included on high-stakes tests. We address this issue directly using the ECLS data. Our student-level regression specifications are based on Equation 5, and control for all of the variables listed in Table 2 as well as state fixed effects and a third degree polynomial of the student's standardized math and reading performance in both the first and third grade waves of the ECLS. Thus, our identification comes only from comparing students with very similar prior learning trajectories who attend schools with similar demographic and academic characteristics but different levels of NCLB pressure because of the state in which they are located.

\footnotetext{
${ }^{24}$ A reduction in science and social studies lessons could be driven by schools using specialists who teach intensive amounts of science and social studies to compensate for decreased lessons from other instructors. However, if we examine hours taught in science or social studies conditional on teaching at least one lesson in the subject we find no support for this explanation.
} 
Panel I of Table 7 displays coefficient estimates for our indicator of whether a school was on the AYP margin. ${ }^{25}$ Estimated coefficients for our indicator that a school is below the AYP margin were never even marginally significant and are not reported for ease of exposition. Our estimates suggest that NCLB pressure has either neutral or positive effects on student achievement in both low- and high-stakes subjects. Students' reading scores are .073 of a standard deviation greater on average when schools are on the AYP margin (Table 7, Panel I, Column 1). This estimate is statistically significant at the .05 level and is a considerably large effect; previous estimates of the impact of accountability pressure on high-stakes tests are typically between 0.1 and 0.2 standard deviations (e.g., Rouse et al., 2007; Rockoff and Turner, 2010). Students' math scores are 0.043 of a standard deviation greater on average when they attend a school that is on the AYP margin, though this estimate is not statistically significant at the 10 percent level. Science scores are also greater (0.049 of a standard deviation), though again this estimate is not statistically significant. Although we are examining results for multiple dependent variables, a power test suggests that these three estimates are far too large to occur by chance. ${ }^{26}$

Importantly, our results also suggest that when schools face NCLB pressure, gains in achievement do not decrease students’ enjoyment of reading or math, or increase anxiety over testing. Respective point estimates for the impact of NCLB pressure on students' enjoyment of reading and math are -0.031 standard deviations (statistically insignificant) and 0.148 standard deviations (significant at the 5 percent level). We also find a small and statistically insignificant decrease of 0.05 standard deviations in students' reported anxiety over testing.

The framework presented in Section 2 motivates the idea that the impacts of NCLB may differ across students within a school. We first examine whether our estimates depend on whether schools faced strong pressure to raise proficiency rates for the overall student population or for the focal student's own subgroup(s). Estimates presented in Panel II come from specifications where we replace the single "on the AYP margin" variable with three mutually exclusive indicators for whether the school was on the AYP margin due to: (1) the overall student group, (2) the student's own subgroup (and not the overall

\footnotetext{
${ }^{25}$ We focus on the AYP margin for most relevant subject(s): math for math test performance or enjoyment, reading for reading test performance or enjoyment, and either math or reading for science test performance or anxiety about standardized tests. We lack power to separate relevant-subject and cross-subject effects using the ECLS.

${ }^{26}$ To test the joint significance of these test score estimates, we simulated estimations of these three models after randomly reassigning schools to different AYP status. Out of 1,000 simulations, none produced three estimates that were, respectively, at least as large in absolute value of as the actual highest, second highest and third highest estimate reported in the first three columns of Panel I of Table 7.
} 
student group as well), and (3) other subgroups (and not the student's own subgroup or the overall student group). The point estimates for all three subjects in Panel II are positive, regardless of whether the students are members of subgroups whose performance is most critical to the schools' AYP ratings, and the relative magnitudes of the three coefficients are different across the three subject areas. Thus, we find no systematic patterns suggesting that our results are driven by targeting particular student subgroups. ${ }^{27}$

To produce the largest increase in student proficiency rates, schools might also direct resources to students who are likely to score close to the threshold of passing the exam. Previous studies find evidence of distributional effects on student achievement on high-stakes exams (e.g., Reback, 2008; Neal and Whitmore Schanzenbach, 2010), and we provide evidence here concerning distributional effects on low-stakes exams. We classify a student as "on the bubble” for passing their state exam if their third grade test score was within 15 percentiles below or 5 percentiles above their states' NCLB exam passing threshold. ${ }^{28}$ The coefficients on the interaction of our indicator for whether a student is "on the bubble" and whether the school is on the AYP margin are generally positive but statistically insignificant (Panel III of Table 7). In other words, students on the bubble of passing high-stakes exams do not appear to perform differently on low-stakes exams when their schools face strong NCLB pressure, although our estimates are too imprecise to rule out small effects.

\section{Conclusion}

As a result of the No Child Left Behind act, virtually every public school in the U.S. is now accountable for meeting measured targets for student test performance, yet our understanding of the impact of NCLB has been hindered by a lack of national data on implementation and nationally comparable data on outcomes. Assembling an extensive national data set of school and student subgroup

\footnotetext{
${ }^{27}$ Of course, it is still possible that schools facing NCLB pressure target resources toward subgroups in ways that affect performance on high-stakes tests. However, the highly reliable examinations in the ECLS provide some assurance that NCLB pressure does not systematically lead to adverse achievement outcomes for students with more or less influence on whether the school makes AYP.

${ }^{28}$ The National Center for Education Statistics (2007) estimates NAEP score equivalents associated with the passing threshold for most states' NCLB exams, and we obtained national percentile equivalents for these NAEP scores. We are unable to do this for eight ECLS states that were not included in the National Center for Education Statistics (2007) publication. Using ranges smaller than 20 percentiles would lead to highly imprecise estimates, and we use a wider range below the cutoffs than above the cutoffs because schools may have anticipated their capacity to improve student performance over time-i.e., most states experienced upward trends in proficiency rates over the first few years of NCLB. For reading and math outcomes our indicator is subject specific; for science tests and test anxiety we use an indicator for being on the bubble in either math or reading.
} 
performance on the examinations required under NCLB, we exploit extensive cross-state variation in rules and standards to examine how NCLB affects school personnel and students. In schools facing strong short-term NCLB pressure, we find that teachers report greater concern over how student test performance will affect their job security and that untenured teachers in high-stakes grades/subjects work longer hours. We also find evidence that schools which will almost certainly fail state requirements in the short term allocate less time to science and social studies instruction, and that untenured teachers in these schools feel much lower job security and expect to exit the teaching profession sooner.

Relative to students in schools facing little NCLB pressure, students in schools facing strong short-term incentives to improve student proficiency raise achievement by 0.07 standard deviations on low-stakes reading exams, do at least as well on low-stakes math and science tests, do not report less enjoyment of reading or math, and do not report more test anxiety. These results do not differ significantly across student subgroups that have differential influence on whether a school fails NCLB requirements, nor between students close to the passing threshold and those farther away.

Our finding that short-term NCLB pressure does not negatively affect student learning or enjoyment of learning is quite important, given widely held concerns about the use of test-based accountability systems. On the other hand, our results also raise questions concerning whether NCLB pressure motivates both tenured and untenured teachers alike, whether talented teachers are discouraged from working in schools with little chance of meeting NCLB requirements, and whether schools neglect low-stakes subjects if their performance lags far below NCLB standards. These issues loom larger every year as NCLB standards become more stringent and more schools fail to meet those standards. As Congress is likely to debate revisions to No Child Left Behind in the near future (see Dillon, New York Times, 2010), policymakers may wish to ensure that schools along the entire performance spectrum face more continuous incentives to improve along a wide array of outcomes. A revised accountability system could offer rewards designed so that incentives are independent of students' prior achievement levels and the scaling of test scores. ${ }^{29}$

Policymakers may also want to consider the large differences in rules and regulations across states, which we as researchers use to identify the effects of NCLB pressure on schools. Thus far, the

\footnotetext{
${ }^{29}$ See Barlevy and Neal (2010) for a detailed discussion and analysis of one example of such a system. They propose a system for rating teacher performance, but a similar system could instead be used to assess school performance.
} 
minutiae of state rules have largely determined the difficulty of meeting AYP. Although a majority of states have adopted "Common Core State Standards" that may increase the consistency of student achievement tests across states, most of the current variation in AYP failure rates across states is not driven by the difficulty of state exams. If policymakers would like to establish more uniformity across states' school accountability standards, then reforms must address the other sources of variation within state formulae. Ideally, accountability pressure should stem from the performance of students along the entire distribution of achievement, rather than the idiosyncrasies of state rules. 


\section{References}

Ballou, D. \& Springer, M.G. (2008). Achievement Trade-Offs and No Child Left Behind. Working Paper. Urban Institute.

Barlevy, G. \& Neal, D. (2010). Pay for Percentile. mimeo, University of Chicago, October 2010.

Booher-Jennings, J. (2005). Below the Bubble: "Educational Triage” and the Texas Accountability System. American Educational Research Journal 42: 231-268.

Brunner, E. \& Imazki, J. (forthcoming). Probation Length and Teacher Salaries: Does Waiting Pay Off? forthcoming in Industrial Relations and Labor Review.

Chakrabarti, Rajashri. (2007). Vouchers, Public School Response, and the Role of Incentives: Evidence from Florida. Federal Reserve Bank of New York Staff Reports, no. 306.

Chiang, H. (2009). How accountability pressure on failing schools affects student achievement. Journal of Public Economics 93, 1045-1057.

Cullen, J.B. \& Reback, R. (2006). Tinkering toward accolades: School gaming under a performance accountability system. In T. Gronberg \& D. Jansen (Eds), Advances in Applied Microeconomics, 14.

Dee, T. \& Jacob, B. (2009). The impact of No Child Left Behind on student achievement. NBER Working Paper No. 15531. Retrieved November 20, 2009, from NBER’s web site: http://www.nber.org/papers/w15531

Dillon, S. (2010). Obama to Seek Sweeping Change in 'No Child' Law. New York Times, February 1, 2010.

Feng, L., Figlio, D., and Sass T. (2010) “School Accountability and Teacher Mobility,” NBER Working Paper 16070.

Figlio, D. (2006). Testing, crime, and punishment. Journal of Public Economics 90, 837-851.

Figlio, D. \& Getzler, L. (2006). Accountability, ability, and disability: Gaming the system? In T. Gronberg \& D. Jansen (Eds), Advances in Applied Microeconomics, 14.

Figlio, D. \& Lucas, M. (2004). What's in a grade? School report cards and the housing market. American Economic Review 94(3), 591-604.

Figlio, D. \& Rouse, C. (2006). Do accountability and voucher threats improve low-performing schools? Journal of Public Economics 90, 239-255.

Figlio, D. \& Winicki, J. (2005). Food for thought? The effects of school accountability plans on school nutrition. Journal of Public Economics 89, 381-394.

Hanushek, E. \& Raymond, M. (2005). Does school accountability lead to improved school performance? Journal of Policy Analysis and Management 24(2), 297 - 327. 
Jacob, B. (2005). Accountability, incentives and behavior: the impact of high-stakes testing in the Chicago Public Schools. Journal of Public Economics 89(5-6), 761-796.

Jacob, B. \& Levitt, S. (2003). Rotten apples: An investigation of the prevalence and predictors of teacher cheating. Quarterly Journal of Economics 118(3), 843-877.

Krieg, J. 2008. Are students left behind? The distributional effects of No Child Left Behind. Education, Finance and Policy 3(2), 250-281.

Ladd, H.F. \& Lauen, D.L. (2009). Status versus growth: The distributional effects of school accountability policies. Working paper. Urban Institute.

Ladd, H.F. \& Zelli, A. (2002). School-based accountability in North Carolina: The responses of school principals. Educational Administration Quarterly 38(4), 494-529.

National Center for Education Statistics. (2007). Mapping 2005 State Proficiency Standards Onto the NAEP Scales (NCES 2007-482). U.S. Department of Education. Washington, DC: Author.

Neal, D. \& Whitmore Schanzenbach, D. (2010). Left behind by design: Proficiency counts and test-based accountability. Review of Economics and Statistics. 92(2): 263-283.

Reback, R. (2008). Teaching to the rating: School accountability and the distribution of student achievement. Journal of Public Economics 92, 1394-1415.

Rockoff, J., and Turner, L. (2010). Short-run Impacts of Accountability on School Quality, American Economic Journal, Economic Policy 2(4): 119-147.

Rouse, C., Hannaway, J., Goldhaber, D., \& Figlio, D. (2007). Feeling the Florida heat? How lowperforming schools respond to voucher and accountability pressure. National Bureau of Economic Research, working paper 13681.

Springer, M.G. (2008). The influence of an NCLB accountability plan on the distribution of student test score gains. Economics of Education Review 27(5), 556-563. 
Figure 1: Distribution of AYP Failure Rates Across States, 2003

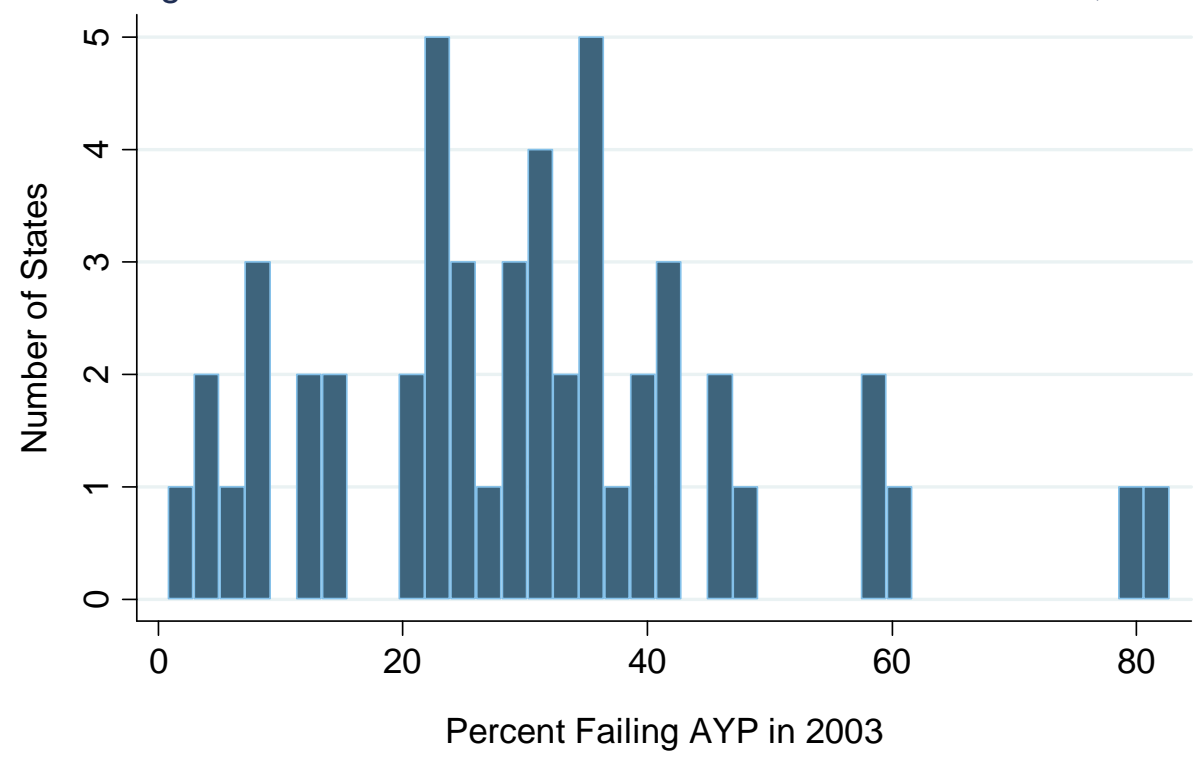


Figure 2: AYP Failure Rates vs. NAEP Proficiency Rates by State, 2003

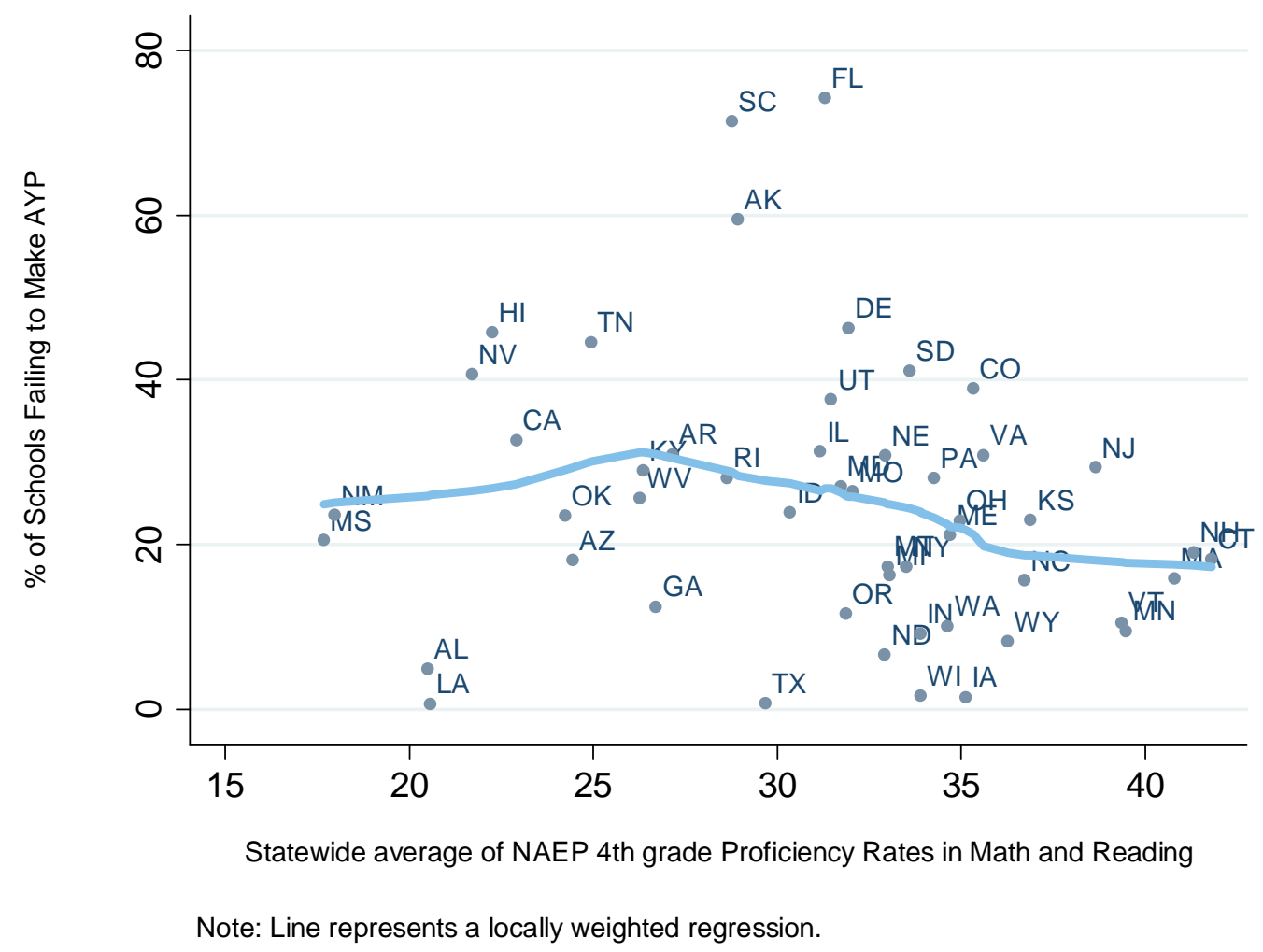

Failure rates are based on schools serving at least five fifth grade students. 
Figure 3: State Variation in the Percentage of Schools Facing NCLB Pressure

\section{Schools on the AYP Margin}

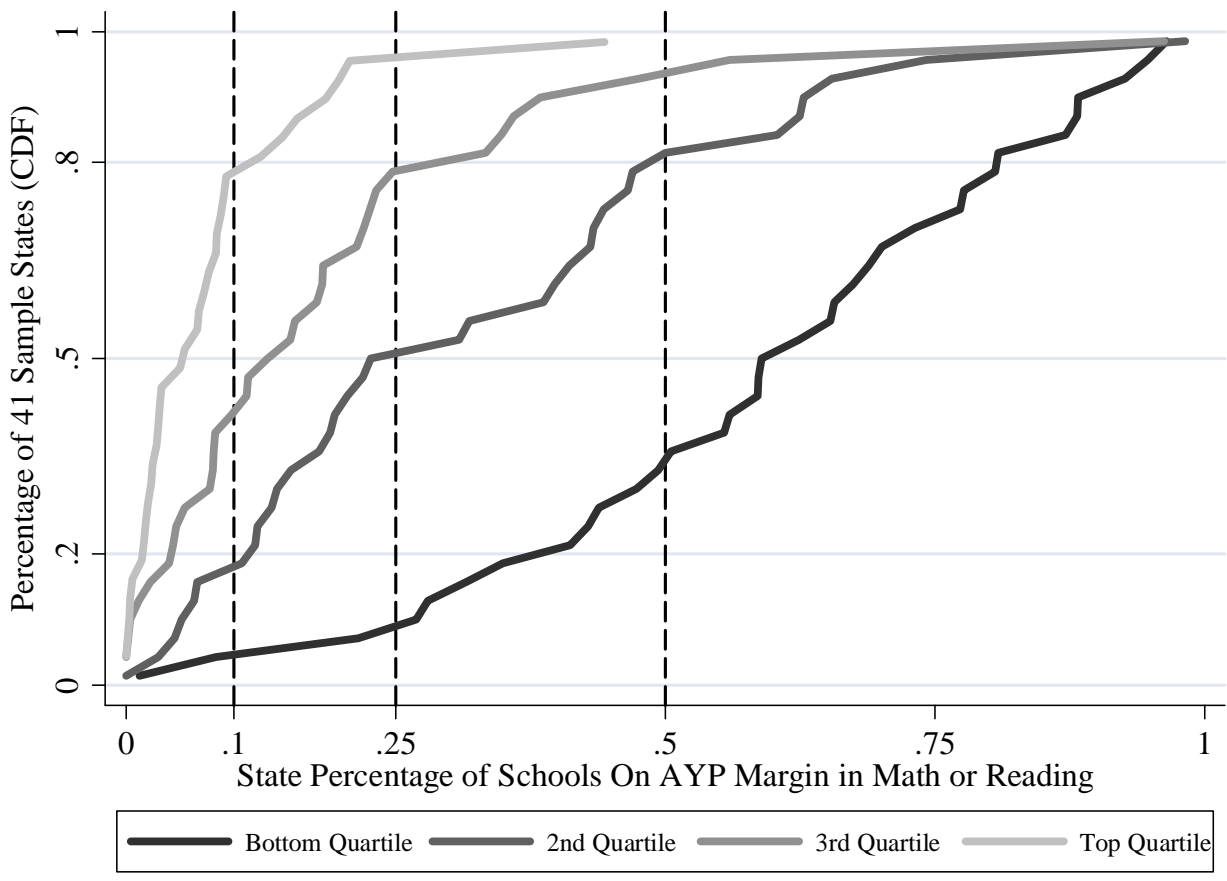

Schools Below the AYP Margin

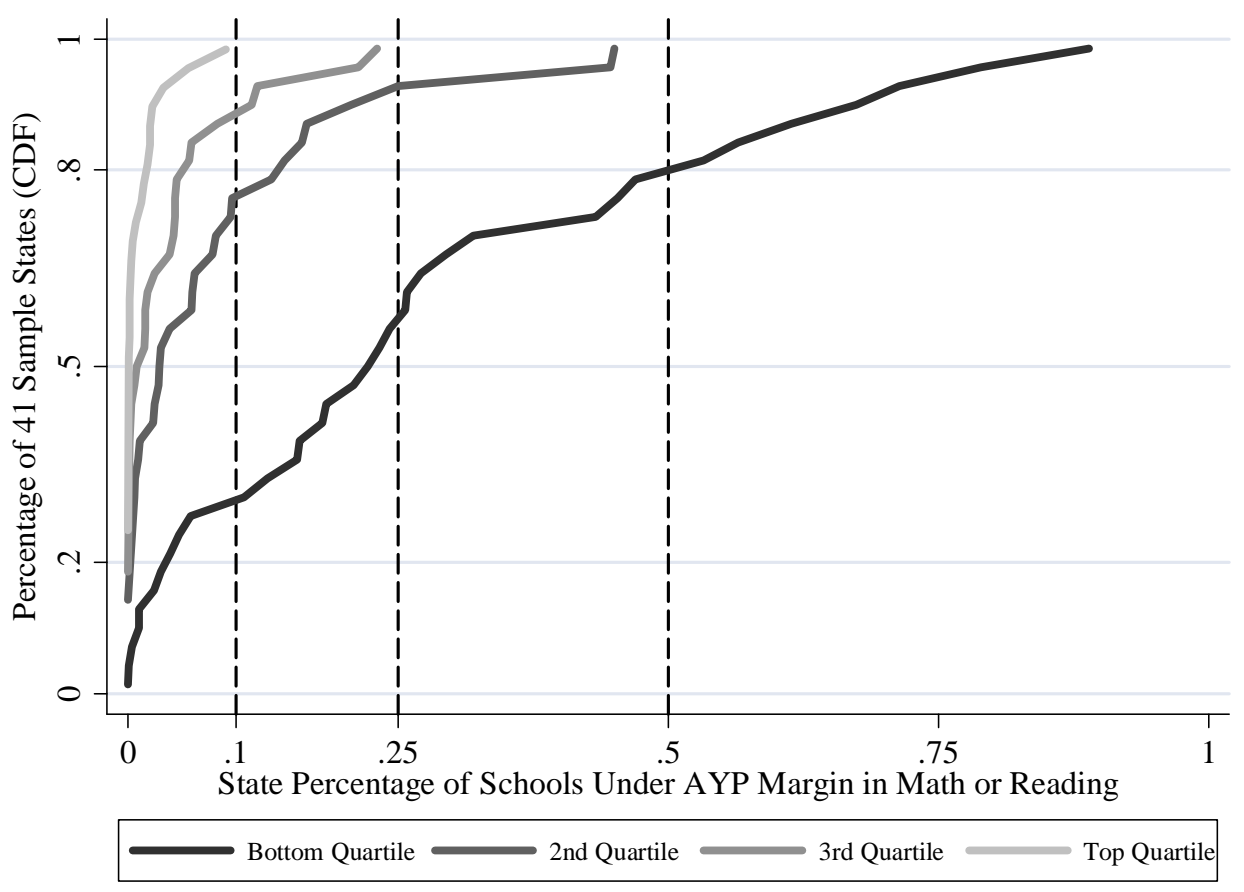

Note: These figures show cumulative distributions of the percentage of schools we consider on the margin of making Adequate Yearly Progress (top panel) and below the margin of making Adequate Yearly Progress (bottom panel) for 2003 and 2004 for the 41 states in our Schools and Staffing Survey analysis. Quartiles reflect schools' positions in their own state’s distribution of student test performance during the school year 2001-2002. 
Table 1: Summary Statistics for Dependent Variables

\begin{tabular}{|c|c|c|}
\hline \multirow{2}{*}{\multicolumn{3}{|c|}{ Teacher-level Dependent Variables from the SASS }} \\
\hline & & \\
\hline Concerned about Job Security due to Student Test Performance & $7.5 \%$ & \\
\hline Plan to Teach Until Retirement & $78 \%$ & \\
\hline Work Hours per weekeek $^{\dagger}$ & 52.4 & 8.91 \\
\hline Instructional Hours per weekeek ${ }^{\dagger}$ & 29.1 & 5.17 \\
\hline Gave at Least One Science Lesson Last Week & $63 \%$ & \\
\hline Gave at Least One Social Studies Lesson Last Week & $65 \%$ & \\
\hline \multicolumn{3}{|l|}{ Untenured Teachers Only: } \\
\hline Concerned about Job Security due to Student Test Performance & $11 \%$ & \\
\hline Plan to Teach Until Retirement & $73 \%$ & \\
\hline Work Hours per week $^{\dagger}$ & 53.8 & 9.46 \\
\hline Instructional Hours per week $^{\dagger}$ & 29.5 & 5.40 \\
\hline \multicolumn{3}{|l|}{ Student-level Dependent Variables from the ECLS } \\
\hline 5th Grade Reading Score (Standardized) & .009 & .967 \\
\hline 5th Grade Math Score (Standardized) & .028 & .982 \\
\hline 5th Grade Science Score (Standardized) & .081 & .950 \\
\hline Enjoyment of Reading (Standardized) & -.002 & 1.01 \\
\hline Enjoyment of Math (Standardized) & .037 & 1.01 \\
\hline Anxiety about standardized tests & $42 \%$ & \\
\hline
\end{tabular}

Notes to Table 1: Means and standard deviations using relevant sample weights provided by the SASS and ECLS to produce nationally representative estimates. The sample is restricted to observations used in the main analyses: teachers in 41 states for the SASS sample and students in 35 states in the ELCS sample. The sample sizes are approximately 7,870 teachers for the SASS sample (1,440 for untenured teachers only) and approximately 6,860 students for the ECLS sample, (rounded to the nearest 10 due to restricted-use data reporting requirements). Standardized variables are Z-scores that were standardized based on the national, cross-sectional student distribution; their means and standard deviations above differ from zero and one respectively because some states/students are omitted due to missing data and because we use longitudinal sampling weights rather than crosssectional sampling weights.

†We set teachers' work-related hours and instructional hours to missing if their reported instructional hours were 60 hours or greater, a suspiciously high level of reported instructional time given the typical five day school week. The work hours per week variable is based on teachers' self-reported hours spent on "all teaching and other schoolrelated activities during a typical full week.” 
Table 2: Descriptive Statistics for Control Variables

\begin{tabular}{|c|c|c|c|c|}
\hline \multirow[b]{2}{*}{ Variable } & \multicolumn{2}{|c|}{ SASS Sample } & \multicolumn{2}{|c|}{ ECLS Sample } \\
\hline & Mean & SD & Mean & SD \\
\hline \multicolumn{5}{|l|}{ School characteristics } \\
\hline Within-state Z-score for 2001-2002 Reading & 0.007 & 0.949 & 0.125 & 0.957 \\
\hline Within-state Z-score for 2001-2002 Math & 0.043 & 0.925 & 0.100 & 0.960 \\
\hline Eligible for Title I & $69 \%$ & & $60 \%$ & \\
\hline Number of enrolled students & 587 & 258 & 587 & 251 \\
\hline Percent Asian students & $4 \%$ & $9 \%$ & $5 \%$ & $10 \%$ \\
\hline Percent Hispanic students & $19 \%$ & $28 \%$ & $16 \%$ & $24 \%$ \\
\hline Percent African American students & $18 \%$ & $26 \%$ & $19 \%$ & $26 \%$ \\
\hline Percent economically disadvantaged students & $47 \%$ & $30 \%$ & $44 \%$ & $30 \%$ \\
\hline Number LEP students in the grade & & & 5 & 13 \\
\hline Missing Number of LEP students in the grade & & & $14 \%$ & \\
\hline \multicolumn{5}{|l|}{ Teacher characteristics (from the SASS) } \\
\hline Total years of experience & 13.9 & 10.1 & & \\
\hline Teaches Math & $77 \%$ & & & \\
\hline Teaches Reading (or English) & $83 \%$ & & & \\
\hline Teaches a high-stakes subject/grade & $34 \%$ & & & \\
\hline Teaches grades 2 or 3 & $41 \%$ & & & \\
\hline Teaches grades 4 or 5 & $42 \%$ & & & \\
\hline Teaches grades 6 or 7 & $14 \%$ & & & \\
\hline Teaches grades 8 or 9 & $7 \%$ & & & \\
\hline Teaches grade 10 or higher & $3 \%$ & & & \\
\hline Teaches grades 2 or 3 and grades 4 or 5 & $15 \%$ & & & \\
\hline Teaches grades 4 or 5 and grades 6 or 7 & $7 \%$ & & & \\
\hline Teaches grades 6 or 7 and grades 8 or 9 & $5 \%$ & & & \\
\hline Teaches grades 8 or 9 and grade 10 or higher & $2 \%$ & & & \\
\hline \multicolumn{5}{|l|}{ Family characteristics (from the ECLS) } \\
\hline Two parent household & & & $67 \%$ & \\
\hline Mother's education level unknown & & & $9 \%$ & \\
\hline Mother has at least a high school diploma & & & $89 \%$ & \\
\hline Mother possesses a B.A. & & & $31 \%$ & \\
\hline Family income missing & & & $16 \%$ & \\
\hline Family income under $\$ 20,000$ & & & $15 \%$ & \\
\hline Family income $\$ 20,000-\$ 35,000$ & & & $18 \%$ & \\
\hline Family income $\$ 35,000-\$ 50,000$ & & & $14 \%$ & \\
\hline Family income $\$ 50,000-\$ 75,000$ & & & $14 \%$ & \\
\hline Family income $\$ 75,000$ - $\$ 100,000$ & & & $11 \%$ & \\
\hline \multicolumn{5}{|l|}{ Student characteristics (from the ECLS) } \\
\hline Reading Z-score in spring 2000 & & & 0.017 & 0.950 \\
\hline Math Z-score in spring 2000 & & & 0.029 & 0.919 \\
\hline Reading Z-score score in spring 2002 & & & -0.001 & 0.981 \\
\hline Math Z-score in spring 2002 & & & 0.029 & 0.970 \\
\hline African American & & & $18 \%$ & \\
\hline Hispanic & & & $20 \%$ & \\
\hline Asian & & & $3 \%$ & \\
\hline Other & & & $5 \%$ & \\
\hline Female & & & $48 \%$ & \\
\hline Date of birth (measured in days) & & & 3/18/93 & 140 \\
\hline
\end{tabular}


Table 3: Predictions of AYP Outcomes

\begin{tabular}{|c|c|c|c|c|c|}
\hline \multicolumn{6}{|l|}{ Panel A: School-wide Outcomes } \\
\hline & On the AYP Margin & \multicolumn{2}{|c|}{ Below the AYP Margin } & \multicolumn{2}{|c|}{ Above the AYP Margin } \\
\hline Percent of Schools & $21.4 \%$ & \multicolumn{2}{|c|}{$9.5 \%$} & \multicolumn{2}{|c|}{$69.1 \%$} \\
\hline Percent Actually Made AYP 2003 and 2004 & $37.9 \%$ & \multicolumn{2}{|c|}{$7.4 \%$} & \multicolumn{2}{|c|}{$86.5 \%$} \\
\hline \multirow[t]{3}{*}{ Panel B: Subgroup Outcomes } & & \multicolumn{4}{|c|}{ Conditional on Numerical Significance } \\
\hline & \multirow{2}{*}{$\begin{array}{l}\text { Numerically Significant } \\
\text { Subgroup }\end{array}$} & \multicolumn{2}{|c|}{ Predicted Moderate Chance } & \multicolumn{2}{|c|}{ Predicted Low Chance } \\
\hline & & Math & Reading & Math & Reading \\
\hline Overall School Population & $92.8 \%$ & $7.2 \%$ & $9.0 \%$ & $2.1 \%$ & $2.5 \%$ \\
\hline Actually made AYP in subject in '03 and '04 & & $51.9 \%$ & $52.4 \%$ & $10.7 \%$ & $8.9 \%$ \\
\hline Economically Disadvantaged & $60.5 \%$ & $14.2 \%$ & $17.4 \%$ & $3.7 \%$ & $4.6 \%$ \\
\hline Actually made AYP in subject in '03 and '04 & & $54.0 \%$ & $53.0 \%$ & $12.8 \%$ & $12.7 \%$ \\
\hline Limited English Proficient & $20.0 \%$ & $18.6 \%$ & $36.7 \%$ & $4.8 \%$ & $10.6 \%$ \\
\hline Actually made AYP in subject in '03 and '04 & & $58.3 \%$ & $49.9 \%$ & $13.5 \%$ & $19.5 \%$ \\
\hline Disabled & $30.0 \%$ & $26.1 \%$ & $30.0 \%$ & $13.9 \%$ & $15.8 \%$ \\
\hline Actually made AYP in subject in '03 and '04 & & $52.0 \%$ & $53.1 \%$ & $14.1 \%$ & $12.3 \%$ \\
\hline White & $69.5 \%$ & $1.2 \%$ & $0.9 \%$ & $0.1 \%$ & $0.0 \%$ \\
\hline Actually made AYP in subject in '03 and '04 & & $55.2 \%$ & $61.5 \%$ & $15.8 \%$ & $25.0 \%$ \\
\hline Black & $29.7 \%$ & $26.9 \%$ & $23.2 \%$ & $9.5 \%$ & $7.8 \%$ \\
\hline Actually made AYP in subject in '03 and '04 & & $51.5 \%$ & $52.5 \%$ & $16.7 \%$ & $15.3 \%$ \\
\hline Hispanic & $28.7 \%$ & $10.9 \%$ & $18.6 \%$ & $1.2 \%$ & $2.7 \%$ \\
\hline Actually made AYP in subject in '03 and '04 & & $56.8 \%$ & $54.6 \%$ & $13.8 \%$ & $15.0 \%$ \\
\hline Asian/Pacific Islander/Filipino & $12.3 \%$ & $0.7 \%$ & $3.5 \%$ & $0.0 \%$ & $25.2 \%$ \\
\hline Actually made AYP in subject in '03 and '04 & & $54.6 \%$ & $53.6 \%$ & $33.3 \%$ & $8.8 \%$ \\
\hline Native American / Alaskan Native & $5.9 \%$ & $14.7 \%$ & $14.5 \%$ & $17.1 \%$ & $22.1 \%$ \\
\hline Actually made AYP in subject in '03 and '04 & & $56.7 \%$ & $52.4 \%$ & $5.7 \%$ & $7.3 \%$ \\
\hline
\end{tabular}

Notes to Table 3: This sample includes all public schools used to estimate Equation 4. These schools provide 2001-2002 student test performance data for the relevant grade level, typically fifth grade. For more details on chosen grade levels, please consult the "Student test performance in focal subject in 2001-2002" row in Appendix 2. 
Table 4: Evidence on NCLB Pressure from the ISBA Survey in California, Georgia, and Pennsylvania

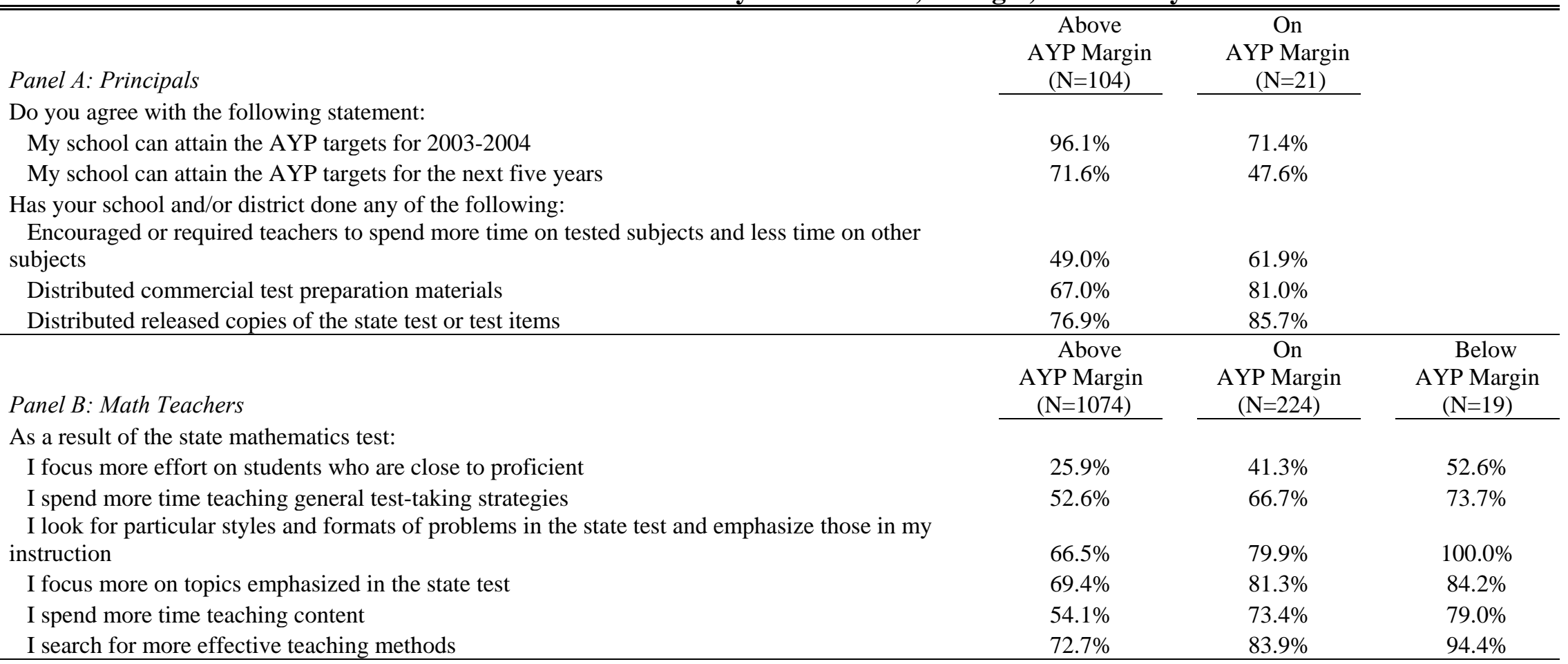

Notes to Table 4: Percentages shown in this table refer to the percentage of respondents who agreed with the corresponding statement. Above, on, and below the AYP margin correspond to our classifications of how likely the school was to make AYP in 2003 and 2004 . See Section 4 of the paper for details. No principal surveyed was in a school classified by our analysis as below the AYP margin. All of the differences in rates between the groups above the AYP margin and either of the other two groups are statistically significant at approximately the .01 level or better. Differences in rates between teachers in schools above the AYP margin and those in schools on the AYP margin are statistically significant at the .05 level for "I focus more effort on students who are close to proficient," and at the .01 level for "I look for particular styles..." and "I search for more effective teaching methods." 
Table 5: Effects of NCLB Pressure on Teacher Attitudes and Work Hours

\begin{tabular}{|c|c|c|c|c|}
\hline & $\begin{array}{c}\text { Concerned about } \\
\text { Job Security due } \\
\text { to Student Test } \\
\text { Performance }\end{array}$ & $\begin{array}{c}\text { Plan to Teach } \\
\text { Until } \\
\text { Retirement }\end{array}$ & $\begin{array}{c}\text { Work Hours } \\
\text { in a Typical } \\
\text { Week }\end{array}$ & $\begin{array}{c}\text { Instructiona } \\
\text { Hours in a } \\
\text { Typical } \\
\text { Week }\end{array}$ \\
\hline \multicolumn{5}{|l|}{$\underline{\text { All Teachers }}$} \\
\hline On the AYP Margin & $\begin{array}{r}-0.011 \\
(.013)\end{array}$ & $\begin{array}{l}0.005 \\
(.024)\end{array}$ & $\begin{array}{l}0.07 \\
(.54)\end{array}$ & $\begin{array}{r}-0.41 \\
(.30)\end{array}$ \\
\hline Below the AYP Margin & $\begin{array}{l}0.025 \\
(.021)\end{array}$ & $\begin{array}{l}0.004 \\
(.035)\end{array}$ & $\begin{array}{r}-1.10 \\
(.84)\end{array}$ & $\begin{array}{l}-1.17^{* *} \\
(.40)\end{array}$ \\
\hline Teach High-stakes & $\begin{array}{l}0.014 \\
(.014)\end{array}$ & $\begin{array}{r}0.008 \\
(.024)\end{array}$ & $\begin{array}{r}-0.41 \\
(.48)\end{array}$ & $\begin{array}{l}-0.27 \\
(.29)\end{array}$ \\
\hline $\begin{array}{l}\text { On the AYP Margin } \\
\text { *Teach High-stakes }\end{array}$ & $\begin{array}{l}0.050 * * \\
(.024)\end{array}$ & $\begin{array}{r}-0.045 \\
(.036)\end{array}$ & $\begin{array}{r}-0.03 \\
(.78)\end{array}$ & $\begin{array}{r}-0.38 \\
(.45)\end{array}$ \\
\hline $\begin{array}{l}\text { Below the AYP Margin } \\
\text { *Teach High-stakes }\end{array}$ & $\begin{array}{l}0.025 \\
(.035)\end{array}$ & $\begin{array}{l}-0.128^{* *} \\
(.046)\end{array}$ & $\begin{array}{r}1.00 \\
(1.02)\end{array}$ & $\begin{array}{r}0.23 \\
(.56)\end{array}$ \\
\hline \multicolumn{5}{|l|}{ Untenured Teachers Only } \\
\hline On the AYP Margin & $\begin{array}{l}0.017 \\
(.042)\end{array}$ & $\begin{array}{l}0.114^{*} \\
(.059)\end{array}$ & $\begin{array}{r}-0.74 \\
(1.44)\end{array}$ & $\begin{array}{l}-1.93^{* *} \\
(.81)\end{array}$ \\
\hline Below the AYP Margin & $\begin{array}{l}0.124^{* *} \\
(.061)\end{array}$ & $\begin{array}{r}0.116 \\
(.083)\end{array}$ & $\begin{array}{r}0.04 \\
(2.04)\end{array}$ & $\begin{array}{l}-2.21^{* *} \\
(1.03)\end{array}$ \\
\hline Teach High-stakes & $\begin{array}{l}0.022 \\
(.043)\end{array}$ & $\begin{array}{l}0.096^{*} \\
(.057)\end{array}$ & $\begin{array}{r}0.87 \\
(1.18)\end{array}$ & $\begin{array}{r}0.19 \\
(.77)\end{array}$ \\
\hline $\begin{array}{l}\text { On the AYP Margin } \\
\text { *Teach High-stakes }\end{array}$ & $\begin{array}{l}0.020 \\
(.064)\end{array}$ & $\begin{array}{r}-0.089 \\
(.087)\end{array}$ & $\begin{array}{r}3.07 \\
(1.94)\end{array}$ & $\begin{array}{r}0.34 \\
(1.18)\end{array}$ \\
\hline $\begin{array}{l}\text { Below the AYP Margin } \\
\text { *Teach High-stakes }\end{array}$ & $\begin{array}{r}-0.050 \\
(.085)\end{array}$ & $\begin{array}{l}-0.286^{* *} \\
(.120)\end{array}$ & $\begin{array}{r}2.70 \\
(2.03)\end{array}$ & $\begin{array}{r}-1.21 \\
(1.31)\end{array}$ \\
\hline
\end{tabular}

Notes to Table 5: Each column displays estimates from two separate teacher-level regressions using data from the 2003-2004 wave of the Schools and Staffing Survey (SASS). The top panel uses a sample of both tenured and nontenured teachers (sample size approximately 7,870), and the bottom panel restricts the sample to untenured teachers (sample size approximately 1,440). Teachers' tenure status is not reported directly in the SASS, so we impute it using teachers' reported years of experience and their states' tenure policies (see footnote 24). All models control for the independent variables with summary statistics listed in the "SASS sample" column of Table 2, and also control for state fixed effects, for a squared term for the number of Limited English proficient students in the grade, for a squared term for the teacher's years of experience, and for squared and cubic terms for schools' within-state standardized 2001-2002 test score performance in both math and reading. All models use the SASS cross-sectional sample weights to make the estimates nationally representative. Bootstrapped standard errors, adjusted for school-level clustering using 1,000 Monte Carlo simulations of both the first-stage and second-stage models, are displayed in parentheses below each estimate.

** significant at .05 level; * significant at .10 level. 


\section{Table 6: NCLB Pressure and Instruction in Low-stakes Subjects}

$\begin{array}{lcc} & \begin{array}{c}\text { Teacher gave at } \\ \text { least one science } \\ \text { lesson last week }\end{array} & \begin{array}{c}\text { Teacher gave at least } \\ \text { one social studies } \\ \text { lesson last week }\end{array} \\ \text { On the AYP Margin } & -0.040 * & -0.013 \\ \text { Below the AYP Margin } & (.024) & (.021) \\ -0.104 * * & -0.062 * * \\ (.038) & (.029)\end{array}$

Notes to Table 6: Each column displays estimates from a teacher-level regression using data from the 2003-2004 wave of the Schools and Staffing Survey (SASS). Sample size is approximately 7,870. These models control for the independent variables with summary statistics listed in the "SASS sample" column of Table 2, except for the indicators for whether the teachers covered math or reading and the indicator for whether the teachers covered a high-stakes grade/subject. Similar to Table 5, the models also control for state fixed effects, for a squared term for the number of Limited English proficient students in the grade, for a squared term for the teacher's years of experience, and for squared and cubic terms for schools' within-state standardized 2001-2002 test score performance in both math and reading. All models use the SASS cross-sectional sample weights to make the estimates nationally representative. Bootstrapped standard errors, adjusted for school-level clustering using 1,000 Monte Carlo simulations of both the firststage and second-stage models, are displayed in parentheses below each estimate.

** significant at .05 level; * significant at .10 level. 
Table 7: Effects of NCLB Pressure on Student Learning and Motivation

\begin{tabular}{|c|c|c|c|c|c|c|}
\hline & Reading Score & Math Score & Science Score & $\begin{array}{l}\text { Enjoyment of } \\
\text { Reading }\end{array}$ & $\begin{array}{l}\text { Enjoyment of } \\
\text { Math }\end{array}$ & $\begin{array}{r}\text { Anxious About } \\
\text { Standardized Tes }\end{array}$ \\
\hline \multicolumn{7}{|l|}{ Panel I (35 states) } \\
\hline On the AYP Margin & $\begin{array}{l}0.073 * * \\
(.033) \\
\end{array}$ & $\begin{array}{r}0.043 \\
(.041) \\
\end{array}$ & $\begin{array}{l}0.049 \\
(.035) \\
\end{array}$ & $\begin{array}{r}-0.031 \\
(.069) \\
\end{array}$ & $\begin{array}{l}0.148^{*} \\
(.082)\end{array}$ & $\begin{array}{r}-0.051 \\
(.037) \\
\end{array}$ \\
\hline \multicolumn{7}{|l|}{ Panel II (35 states) } \\
\hline \multicolumn{7}{|c|}{ On the AYP Margin based on the performance of... } \\
\hline Overall student group & $\begin{array}{r}0.010 \\
(.051)\end{array}$ & $\begin{array}{r}0.092 \\
(.073)\end{array}$ & $\begin{array}{r}0.040 \\
(.058)\end{array}$ & $\begin{array}{l}0.061 \\
(.116)\end{array}$ & $\begin{array}{l}0.282^{* *} \\
(.144)\end{array}$ & $\begin{array}{l}0.005 \\
(.063)\end{array}$ \\
\hline Student's subgroup (not overall) & $\begin{array}{l}0.053 \\
(.051)\end{array}$ & $\begin{array}{r}0.014 \\
(.074)\end{array}$ & $\begin{array}{r}0.074 \\
(.05)\end{array}$ & $\begin{array}{l}-0.012 \\
(.103)\end{array}$ & $\begin{array}{l}0.109 \\
(.153)\end{array}$ & $\begin{array}{c}-0.038 \\
(.05)\end{array}$ \\
\hline $\begin{array}{l}\text { Other subgroup(s) (not overall or } \\
\text { student's subgroup) }\end{array}$ & $\begin{array}{l}0.108^{* *} \\
(.041)\end{array}$ & $\begin{array}{r}0.030 \\
(.051)\end{array}$ & $\begin{array}{l}0.034 \\
(.038)\end{array}$ & $\begin{array}{l}-0.078 \\
(.082)\end{array}$ & $\begin{array}{l}0.099 \\
(.099)\end{array}$ & $\begin{array}{l}-0.086 * \\
(.044)\end{array}$ \\
\hline \multicolumn{7}{|l|}{ Panel III (27 states) } \\
\hline $\begin{array}{l}\text { On the AYP Margin * } \\
\text { Student on the bubble for Passing }\end{array}$ & $\begin{array}{r}-0.035 \\
(.060)\end{array}$ & $\begin{array}{l}0.080 \\
(.090)\end{array}$ & $\begin{array}{l}0.075 \\
(.053)\end{array}$ & $\begin{array}{l}0.113 \\
(.147)\end{array}$ & $\begin{array}{l}0.081 \\
(.191)\end{array}$ & $\begin{array}{l}0.018 \\
(.064)\end{array}$ \\
\hline On the AYP Margin & $\begin{array}{l}0.056 \\
(.039)\end{array}$ & $\begin{array}{r}-0.013 \\
(.047)\end{array}$ & $\begin{array}{l}0.034 \\
(.039)\end{array}$ & $\begin{array}{l}0.002 \\
(.078)\end{array}$ & $\begin{array}{l}0.146 \\
(.101)\end{array}$ & $\begin{array}{l}-0.059 \\
(.044)\end{array}$ \\
\hline
\end{tabular}

Notes to Table 7: Each column displays estimates from three student-level models using data from the Early Childhood Longitudinal Survey-Kindergarten Cohort (ECLS). Panel I displays estimates of the coefficient on whether the school was on the AYP margin in the relevant subject: math for math test performance or enjoyment, reading for reading test performance or enjoyment, and either math or reading for science test performance or anxiety about standardized tests. To decompose the first panel results by the type of subgroup(s) that were on the AYP margin, Panel II's models use three mutually exclusive indicators that sum to "On the AYP Margin” variable. Panel III's models use the same independent variable as in Panel I, but add an interaction term with a dummy variable for whether the student is on the bubble for passing the state's NCLB exam in the relevant subject; this dummy variable also enters the model separately and its creation is described in the text of Section 5. All models control for the variables listed in the "ECLS sample" column of Table 2, plus state fixed effects, an indicator for whether the school is predicted to be below the margin for making AYP, and squared and cubic terms for the student's standardized math and reading performance in both the first and third grade waves of the ECLS. Dependent variables are from the fifth grade wave of the ECLS. Sample sizes are approximately 6,860 students for the first two panels and 5,630 students for Panel III, (rounded to the nearest 10 to comply with data reporting requirements). The smaller sample for Panel III is due to missing information concerning the difficulty of six states' NCLB exams. The estimates in Panels I and II remain fairly similar if we restrict the sample to the roughly 5,630 observations used to estimate the models of Panel III. All models weight observations using the student-level longitudinal sample weights provided in the ECLS data. Bootstrapped standard errors, adjusted for school-level clustering using 1,000 Monte Carlo simulations of both the first-stage and second-stage models, are displayed in parentheses below each estimate.

** significant at .05 level; * significant at .10 level. 


\section{Appendix 1. Sources of Collected AYP Data}

\begin{tabular}{|c|c|c|c|c|}
\hline \multirow[b]{2}{*}{ States in 2002-2003 } & $\begin{array}{l}\text { Available in } \\
\text { existing } \\
\text { databases }\end{array}$ & $\begin{array}{l}\text { We have } \\
\text { collected }\end{array}$ & Not available & $\begin{array}{l}\text { State Abbreviations } \\
\text { Where Data are Not } \\
\text { Available }\end{array}$ \\
\hline & & & & \\
\hline School made AYP & 24 & 44 & 0 & - \\
\hline Subgroup made AYP & 5 & 38 & $9^{\mathrm{i}}$ & $\begin{array}{l}\text { AL }{ }^{\mathrm{ii}} \text {, IA, ME, NE, NM, } \\
\text { ND, OK, WI, WY }\end{array}$ \\
\hline $\begin{array}{l}\text { Percent proficient by } \\
\text { subgroup }\end{array}$ & 16 & 41 & 5 & AL, ME, NE, NH, WV \\
\hline $\begin{array}{l}\text { Number of students in } \\
\text { subgroup }\end{array}$ & 2 & 34 & 15 & $\begin{array}{c}\text { AL, CO, DE, HI, ID, IA, } \\
\text { ME, MS, NE, ND, OH, } \\
\text { OK, SD, WV, WY }\end{array}$ \\
\hline \multicolumn{5}{|l|}{ States in 2003-2004 } \\
\hline School made AYP & 48 & 46 & 0 & - \\
\hline Subgroup made AYP & 39 & 40 & 4 & IA, NE, NM, ND \\
\hline $\begin{array}{l}\text { Percent proficient by } \\
\text { subgroup }\end{array}$ & 16 & 44 & 3 & AL, NE, NH \\
\hline $\begin{array}{l}\text { Number of students in } \\
\text { subgroup }\end{array}$ & 1 & 37 & 10 & $\begin{array}{l}\text { CO, ID, IA, ME, MS, } \\
\text { NE, ND, OH, SD, WY }\end{array}$ \\
\hline \multicolumn{5}{|c|}{$\begin{array}{l}\text { Notes to Appendix 1: Existing databases refer to School Data Direct and the National AYP and Identification Database } \\
\text { Number of states per row can exceed } 50 \text { because we collected data in states included in existing databases. } \\
\text { (i) For schools in Arizona, New Jersey, and Pennsylvania, due to otherwise missing data, we impute whether some } \\
\text { subgroups made AYP in 2002-2003 using their 2002-2003 proficiency rates and their states' published standards. } \\
\text { (ii) Although Alabama did not publish whether student subgroups made AYP in 2002-2003, we can include Alabama schools } \\
\text { in our analyses because Alabama (incorrectly) did not even base schools' AYP status in 2002-2003 on student subgroup } \\
\text { performance. }\end{array}$} \\
\hline
\end{tabular}




\section{Appendix 2: Predicting the Probability of Making AYP}

We run state-specific regressions using the data described below to generate predictions of the likelihood that each numerically-significant student subgroup and (by extension) their school would pass AYP in the spring of both 2003 and 2004 in the subjects of reading and math. To be as consistent as possible in our state-by-state predictions of which student subgroups were on the AYP margin, we applied a set of rules to the construction of data to generate subgroup-level AYP failure predictions. The table on the following page explains the data construction in detail.

We use a specific subgroup's 2001-2002 proficiency rate wherever available to predict that subgroup's likelihood of making AYP in 2003 and 2004 (note these are cross-sectional measures of a subgroup's performance). For privacy protection, the 2001-2002 test score data is typically missing for groups below a state-determined minimum size (e.g., fewer than 20 students). Thus, for schools where subgroup enrollment grew between 2001-2002 and 2004, there might be AYP determinations for a subgroup in 2004 but no 2001-2002 proficiency rate. (In the rare case, the 2001-2002 suppression rules redacted data for groups larger than minimum subgroup size requirements for AYP accountability.) To retain these cases in our sample, we specified an alternate version of the probit regression, where we assign the school-wide 2001-2002 proficiency rate to all student subgroups within the school regardless of whether we possessed subgroup-specific 2001-2002 proficiency rates. In this case, we add an interaction term with a variable measuring the fraction of the school-wide population composed of students in the relevant subgroup. We then use predictions from the alternate probit version in cases when predictions were missing from the main specification.

Sometimes entire subgroups were dropped from probit regressions when there was not any withinsubgroup variation in the subject in the state (e.g., there were only 11 numerically-significant Asian subgroups in 2004 among Washington's elementary schools and all 11 passed AYP their math and reading proficiency targets). In cases where subgroups' success or failure was perfectly determined, we overwrote their missing probabilities of making AYP with predicted probabilities obtained from OLS regressions that used the same set of predictors. This practice was of little consequence, because subgroups in these cases were always classified as having either low or high likelihoods of making AYP (they never fall in the moderate category). 


\begin{tabular}{|c|c|c|}
\hline \multicolumn{3}{|c|}{ Model Specification and Data Construction for State Probits Estimating Likelihood of Making AYP in 2003 and 2004} \\
\hline Variable description & Data sources & Variable coding \\
\hline \multicolumn{3}{|l|}{ Dependent variable } \\
\hline $\begin{array}{l}\text { Subject-specific subgroup AYP } \\
\text { proficient indicator } \\
\text { Subjects are math and reading. } \\
\text { Student subgroups are: school-uide; } \\
\text { African American; Asian/Pacific } \\
\text { Islander; Hispanic; White; Native } \\
\text { American; Limited English Proficient; } \\
\text { Disabled; Economically } \\
\text { Disadvantaged; Flipino (when used } \\
\text { by state); Asian (when used by } \\
\text { state); Pacific Islander (When used by } \\
\text { state); and Alaskan Native (when } \\
\text { used by state). }\end{array}$ & $\begin{array}{l}\text { Wherever available, school report card data from states' } \\
\text { departments of education listing state's onn determinations } \\
\text { of whether student subgroups passed their proficiency } \\
\text { targets in the years } 2002-2003 \text { and } 2003-2004 \text {. State's final } \\
\text { yes/no determinations typically account for all forms of } \\
\text { adjustment of subgroup raw proficiency rates (e.g., 2- or 3- } \\
\text { year averaging; confidence intervals; safe harbor; and } \\
\text { appeals). } \\
\text { When not available from state DOE sources, data is from } \\
\text { SchoolDataDirect.org or the National AYP and Identification } \\
\text { Database (for 2003-2004 only). } \\
\text { In two states which lacked 2002-2003 proficiency target } \\
\text { data fromall three sources of data, we constructed the } \\
\text { variable using each state's published raw subgroup } \\
\text { proficiency rates, which we adjusted using the state's } \\
\text { documented confidence interval methods (if applicable) to } \\
\text { determine whether each subgroup passed, failed, or was } \\
\text { not applicable. This approximation method had greater than } \\
90 \% \text { accuracy when tested in two populous states with } \\
\text { complete data. }\end{array}$ & $\begin{array}{l}\text { Equals } 0 \text { if the subgroup failed its AYP subject-specific proficiency target } \\
\text { in either } 2002-2003 \text { or } 2003-2004 \text {. } \\
\text { Equals } 1 \text { if the subgroup (a) passed its AYP proficiency target in the } \\
\text { given subject in } 2002-2003 \text { and } 2003-2004 \text {, or (b) passed in one year } \\
\text { and numerically insignificant in the other year. } \\
\text { Equals missing if the subgroup was numerically insignificant in both } \\
\text { years (according to the state's own definition of numerical significance). } \\
\text { For states that further break out AYP proficiency targets by grade level } \\
\text { or grade span, subgroup indicators are specific to each accountable } \\
\text { grade level/span, using the same rules for creating values of missing, } \\
\text { zero, or one. } \\
\text { Two states did not use subgroup-level pass rates to determine schools' } \\
\text { AYP status in 2002-2003. In each case, only } 2004 \text { subgroup-level AYP } \\
\text { proficiency target data was used to construct the dependent variable. } \\
\text { Two states only published whether the subgroup passed AYP in each } \\
\text { subject overall (a measure that includes both the subgroup's proficiency } \\
\text { rate and its participation rate for that subject). In these cases, we used } \\
\text { this overall subject measure in lieu of proficiency-only indicators. }\end{array}$ \\
\hline \multicolumn{3}{|l|}{ Independent variables } \\
\hline $\begin{array}{l}\text { Subgroup test performance in } \\
\text { focal subject in 2001-2002 } \\
\text { (entered into model as linear, } \\
\text { squared, and cubed terms) }\end{array}$ & $\begin{array}{l}\text { National Longitudinal School-Level State Assessment Score } \\
\text { Database }\end{array}$ & $\begin{array}{l}\text { When available, we use the subgroup's unadjusted } 5^{\text {th }} \text { grade proficiency } \\
\text { rate on the statewide test administered in } 2001-2002 \text { for the focal } \\
\text { subject. (We selected grade } 5 \text { because our second stage of analysis } \\
\text { examines ECLS student outcomes in } 2003-2004 \text {, when the majority of } \\
\text { ECLS students are fifth graders.) } \\
\text { For states not reporting performance for particular subgroups, we use } \\
\text { the overall student performance in the focal subject in the selected grade } \\
\text { level in that school. As described in the text, we supplement those } \\
\text { models with interaction terms between the test performance variable and } \\
\text { the fraction of students who are members of that subgroup. } \\
\text { For } 6 \text { states where proficiency rates are unavailable, we instead use the } \\
\text { reported percentile rank scores or scale scores. }\end{array}$ \\
\hline
\end{tabular}




\begin{tabular}{|c|c|c|}
\hline \multicolumn{3}{|c|}{ Model Specification and Data Construction for State Probits Estimating Likelihood of Making AYP in 2003 and 2004} \\
\hline Variable description & Data sources & Variable coding \\
\hline & & $\begin{array}{l}\text { For states that did not test grade } 5 \text { in 2001-2002, we use the next closest } \\
\text { lower tested grade level (i.e., grade 4, grade 3) or, if that is unavailable, } \\
\text { the next closest higher tested grade (i.e., grade } 6 \text {, grade } 7 \text { ). The models } \\
\text { then include observations for all schools in that state with test } \\
\text { performance variables in the relevant grade levels. When these models } \\
\text { include test performance from two different grade levels (e.g., } 4^{\text {th }} \text { and } \\
6^{\text {th) }} \text {, we also include a dichotomous dummy variable indicating whether } \\
\text { the test variable values come from students in the higher grade. } \\
\text { In states that further break out subgroups' AYP proficiency targets by } \\
\text { grade levels or grade spans, we run separate models for each high- } \\
\text { stakes grade for schools serving } 5^{\text {th }} \text { graders. Depending on availability, } \\
\text { we use } 2001-2002 \text { test performance variables from either the same } \\
\text { grade, the next lowest grade, or the next highest grade. }\end{array}$ \\
\hline $\begin{array}{l}\text { Pct. that the student subgroup } \\
\text { comprised of the denominator for } \\
\text { its } 2001-2002 \text { proficiency rate } \\
\text { value } \\
\text { (entered as a main effect, and } \\
\text { interacted with the three } 2002 \\
\text { proficiency rate terms) }\end{array}$ & $\begin{array}{l}\text { National Longitudinal School-Level State Assessment Score } \\
\text { Database } \\
\text { Where student subgroup size not present in State } \\
\text { Assessment Score database, data is from the Common } \\
\text { Core of Data. }\end{array}$ & $\begin{array}{l}\text { Equals } 1 \text { when the subgroup's own proficiency rate available from 2001- } \\
2002 \text {. Othernise, ranges from O to 1, and is equal to the ratio of enrolled } \\
\text { students in the given subgroup in } 2001-2002 \text { within the school (from } \\
\text { CCD) to the total number of enrolled students in the school. Since data } \\
\text { about the number of LEP students and disabled students is not available } \\
\text { at the school level in the CCD, we substituted in 2003-2004 AYP } \\
\text { subgroup size ratios for the LEP and disabled subgroups. If this } \\
\text { subgroup size data not available in a state for 2003-2004, then we use } \\
\text { district-level LEP and disabled ratios (applicable to three states). }\end{array}$ \\
\hline $\begin{array}{l}\text { Size of the student subgroup in } \\
\text { 2003-2004 } \\
\text { (entered as } 1 / \text { sqrt(size), and this term } \\
\text { is also interacted with the three } 2002 \\
\text { proficiency rate terms and the three } \\
2002 \text { proficiency rate } \times 2002 \text { pct. } \\
\text { group interaction terms) }\end{array}$ & $\begin{array}{l}\text { Wherever available, school report card data from state } \\
\text { departments of education that list student subgroup size } \\
\text { (using AYP definitions). Where not available from state } \\
\text { sources, then dramn from 2003-2004 data in the National } \\
\text { Longitudinal School-Level State Assessment Score } \\
\text { Database or the 2003-2004 Common Core of Data. }\end{array}$ & $\begin{array}{l}\text { This variable is derived from the state's count of continuously enrolled } \\
\text { students per student subgroup accountable under NCLB (note that } \\
\text { states' definitions of "continuous enrollment" for the purposes of AYP } \\
\text { accountability differ somewhat from state definitions for state } \\
\text { accountability systems or just cross-sectional enrollment counts as of the } \\
\text { fall in the school year). } \\
\\
\text { Where state sources are not available, size is estimated using } 2004 \\
\text { State Assessment Score data about number of students tested per } \\
\text { subgroup. If this source is not available for the state, we used grade- } \\
\text { specific CCD enrollment data and district-level LEP and disabled ratios } \\
\text { and applied them to school-by-grade-level membership. }\end{array}$ \\
\hline
\end{tabular}




\begin{tabular}{|c|c|c|}
\hline \multicolumn{3}{|c|}{ Model Specification and Data Construction for State Probits Estimating Likelihood of Making AYP in 2003 and 2004} \\
\hline Variable description & Data sources & Variable coding \\
\hline $\begin{array}{l}\text { Indicators for years held } \\
\text { accountable }\end{array}$ & $\begin{array}{l}\text { The same data source used to obtain the dependent } \\
\text { variable. }\end{array}$ & $\begin{array}{l}\text { Two dichotomous variables indicating whether the subgroup was only } \\
\text { numerically significant in } 2003 \text { (but not 2004) in the focal subject and, } \\
\text { vice versa, numerically significant in } 2004 \text { (but not 2003) in the focal } \\
\text { subject. The omitted category is the subgroup is numerically significant } \\
\text { in both } 2003 \text { and } 2004 \text {. }\end{array}$ \\
\hline Subgroup indicators & Constructed & $\begin{array}{l}\text { A series of dichotomous variables indicating the student subgroup to } \\
\text { which the observation belongs. The omitted category is the campus- } \\
\text { wide student group. }\end{array}$ \\
\hline $\begin{array}{l}\text { School-level characteristics in } \\
\text { 2001-2002: } \\
\text { (a) percent of students who are } \\
\text { black } \\
\text { (b) percent of students who are } \\
\text { (c) Hispanic } \\
\text { (c) Ascent of students who are } \\
\text { (d) percent of students who qualify } \\
\text { for a free- or reduced-price } \\
\text { meal } \\
\text { (e) whether the school is Title I } \\
\text { eligible } \\
\text { (f) total student membership }\end{array}$ & Common Core of Data 2001-2002 school-level data & $\begin{array}{l}\text { We constructed the racial and economic demographic using total student } \\
\text { membership as the denominator. In cases where categories of school- } \\
\text { level data were missing from } 2002 \text { state files, the variables were } \\
\text { constructed using the next closest year in which those variables were } \\
\text { present in CCD files (2000-2001, then 2002-2003, then 1999-2000, etc.) }\end{array}$ \\
\hline
\end{tabular}

